\title{
Fundamental Science and Technology of Flash Processing Robustness for Advanced High Strength Steels (AHSS)
}

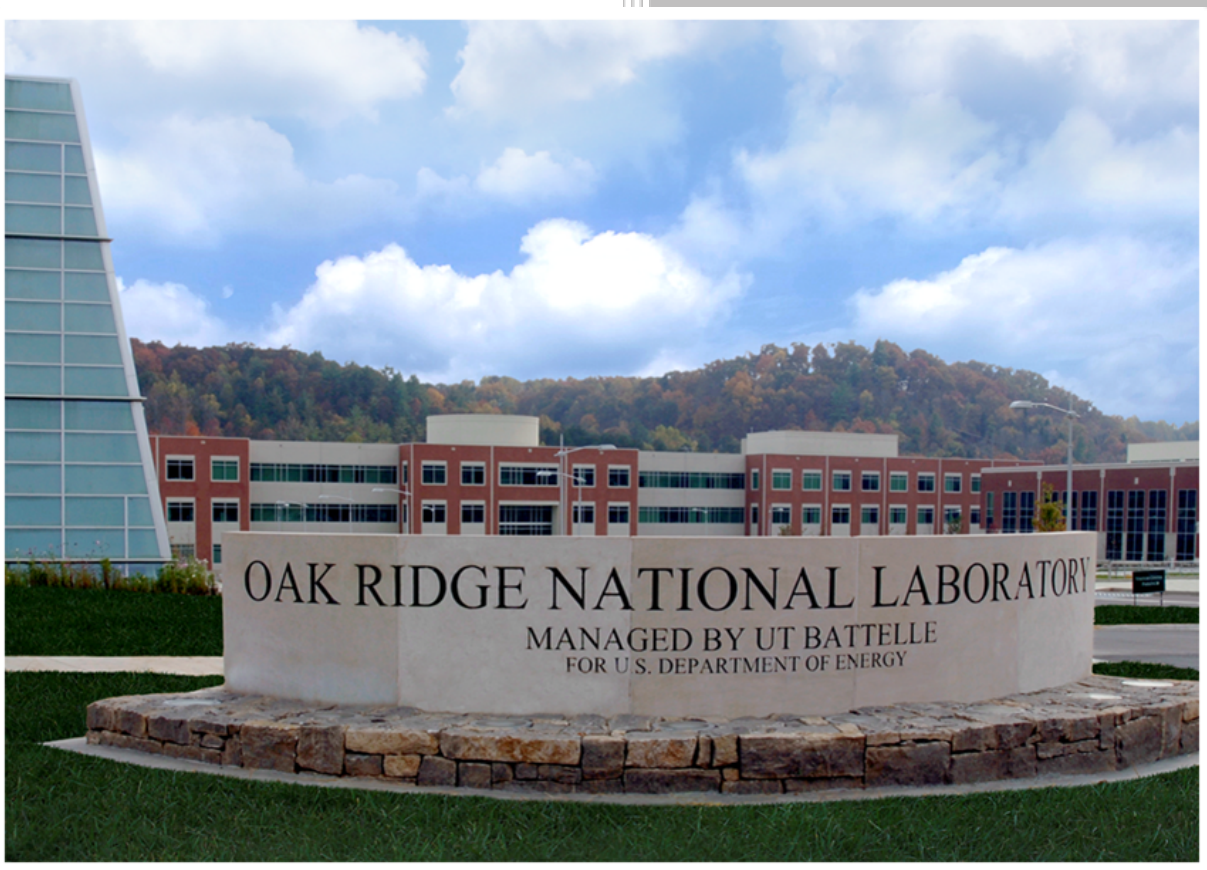

Approved for public release. Distribution is unlimited
Thomas R. Watkins Gary Cola Suresh Babu Thomas Muth Ben Shassere Hsin Wang Ralph Dinwiddie

October 2019 


\title{
DOCUMENT AVAILABILITY
}

Reports produced after January 1, 1996, are generally available free via US Department of Energy (DOE) SciTech Connect.

Website www.osti.gov

Reports produced before January 1, 1996, may be purchased by members of the public from the following source:

\author{
National Technical Information Service \\ 5285 Port Royal Road \\ Springfield, VA 22161 \\ Telephone 703-605-6000 (1-800-553-6847) \\ TDD 703-487-4639 \\ Fax 703-605-6900 \\ E-mail info@ntis.gov \\ Website http://classic.ntis.gov/
}

Reports are available to DOE employees, DOE contractors, Energy Technology Data Exchange representatives, and International Nuclear Information System representatives from the following source:

Office of Scientific and Technical Information

PO Box 62

Oak Ridge, TN 37831

Telephone 865-576-8401

Fax 865-576-5728

E-mail reports@osti.gov

Website http://www.osti.gov/contact.html

This report was prepared as an account of work sponsored by an agency of the United States Government. Neither the United States Government nor any agency thereof, nor any of their employees, makes any warranty, express or implied, or assumes any legal liability or responsibility for the accuracy, completeness, or usefulness of any information, apparatus, product, or process disclosed, or represents that its use would not infringe privately owned rights. Reference herein to any specific commercial product, process, or service by trade name, trademark, manufacturer, or otherwise, does not necessarily constitute or imply its endorsement, recommendation, or favoring by the United States Government or any agency thereof. The views and opinions of authors expressed herein do not necessarily state or reflect those of the United States Government or any agency thereof. 
Material Science and Technology Division

\title{
Fundamental Science and Technology of Flash Processing Robustness for Advanced High Strength Steels (AHSS)
}

\author{
Thomas R. Watkins ${ }^{1}$ \\ Suresh $\mathrm{Babu}^{2}$ \\ Gary M. Cola, Jr. ${ }^{3}$ \\ Thomas Muth ${ }^{1}$ \\ Ben Shassere ${ }^{1}$ \\ Hsin Wang \\ Ralph Dinwiddie

\footnotetext{
${ }^{1}$ Material Science and Technology Division, ORNL, Oak Ridge, TN 37831, USA

${ }^{2}$ Department of Mechanical, Aerospace, and Biomedical Engineering, The University of Tennessee, Knoxville, TN 37996, USA

${ }^{3}$ SFP Works LLC, Washington, MI 48095, USA
}

October 2019

Prepared by

OAK RIDGE NATIONAL LABORATORY

Oak Ridge, TN 37831-6283

managed by

UT-BATTELLE, LLC

for the

US DEPARTMENT OF ENERGY

under contract DE-AC05-00OR22725 



\section{CONTENTS}

$\begin{array}{ll}\text { ACKNOWLEDGMENTS } & 4\end{array}$

$\begin{array}{ll}\text { ABSTRACT } & 4\end{array}$

$\begin{array}{ll}\text { 1. OBJECTIVE } & 4\end{array}$

2. BACKGROUND 4

3. TASKS: RESULTS AND DISCUSSION 4

3.1 TASK 1: MATERIAL SELECTION AND ACQUISITION 5

3.2 TASK 3: THERMAL MEASUREMENTS AND FLASH PROCESSING 5

3.3 TASKS 2, 4, 5: CHARACTERIZATIONS AND FORMABILITY LIMITS 11

3.4 TASK 6: CORRELATION OF PROCESSING, STRUCTURE, AND PROPERTIES 25

3.5 TASK 7: MODELING OF THERMAL TRANSIENTS AND FORMABILITY 28

3.6 TASK 8: PRODUCE GUIDELINES FOR SCALING UP FLASH PROCESSING 29

3.7. PUBLICATIONS AND PRESENTATIONS 29

3.8. REFERENCES 29

APPENDIX A $\quad$ A-1 


\title{
ACKNOWLEDMENT
}

The authors thank the support of the U.S. Department of Energy, Energy Efficiency \& Renewable Energy Advance Manufacturing office and the guidance of our Technology Managers, Dr.s David Forrest and Steve Sikirica. The authors acknowledge Dr.s Donovan Leonard and Artem Trofimov for the TEM work and confirmatory IR thermography work, respectively.

\begin{abstract}
"Flash processed" low carbon steel sheets were characterized using in-situ IR imaging, ex-situ dome deformation testing and microscopy. Due to flash processing set-up, cooling water flow and steam interfered with robust infrared temperature measurements. Though preliminary, rapidly heating the steel sheet to greater than $1170^{\circ} \mathrm{C}$ and then water quenching a few seconds later can result in through thickness microstructural gradients, where the center is harder than the exterior surfaces. This microstructural configuration sometimes results in a dome displacement $\sim 75 \%$ relative to that observed in the more ductile as-received material. The presence of aluminum nitride (AlN) inclusions was confirmed, a likely byproduct from a de-oxidization reaction, and may reduce dome displacement (similar to strain to failure) significantly. Based on thermodynamic calculations, a high flash processing temperature $\left(>1170^{\circ} \mathrm{C}\right)$ is recommended to dissolve these AlN inclusions in the austenite phase.
\end{abstract}

\section{OBJECTIVES}

The objectives of this project include the evaluation of the spatial variations of initial microstructure in plain carbon steels, measurements of spatial and temporal variations in heating rate, peak temperature, dwell time, cooling rate, as well as, quantification of spatial variations in final microstructure. These variations will be correlated to the scatter in the dome testing, and these correlations will then be used to develop guidelines for manufacturing scaling up of the Flash ${ }^{\circledR}$ processing for sheet metal with width greater than $300 \mathrm{~mm}$, as well as, wide range of thicknesses (e.g. 0.5 to $2.5 \mathrm{~mm}$ ) relevant for automotive applications.

\section{BACKGROUND}

The project was initiated on October 1, 2015 under the FY 2016 AOP; funding became available for work to begin on December 21, 2015. SFP Works, Inc. (now Flash Steelworks) developed a novel process for rapid heat treatment to produce high strength, high formability, economical steels for automotive applications. Initial funding through the SBIR program has shown very promising results including several stamped parts and key collaborations with OEMs. This program seeks to address key questions about the uniformity of the product at a manufacturing scale, and de-risks the technology for private investment.

\section{TASKS: RESULTS AND DISCUSSION}

There were eight tasks/milestones as follows:

Task 1: Material selection and acquisition.

Task 2: Initial microstructural characterization.

Task 3: Thermal measurements and flash processing.

Task 4: Microstructural characterization of flashed sheet.

Task 5: Tensile and formability limits.

Task 6: Correlation of Processing, Structure, and Properties.

Fask 7: Modeling of Thermal Transients and Formability: Became beyond the scope of project.

Task 8: Produce Guidelines for Scaling Up Flash Processing. 
In order to improve flow for the reader, Tasks 2, 4 and 5 were merged for reporting purposes. Further, this report is a compilation of quarterly reports [Watkins et al. 2016-2019] over the duration of the project with large portions reproduced verbatim from these reports or with minor modifications.

\subsection{TASK 1: MATERIAL SELECTION AND ACQUISITION}

SFP works acquired the commercial off-the-shelf steel sheet for three of four compositions: AISI 1010, AISI 1020 and AISI 1030 which has nominally $0.001,0.002$ and $0.003 \mathrm{~g} \mathrm{~d} / \mathrm{g}_{\text {steel }}$ respectively (see Table I). Procurement of the 1010 and 1020 steel sheet was straightforward. However, procurement of the AISI 1030 and 1040 steels was surprisingly difficult. The 1030 sheet was only found in Turkey. The shipment of our order was turned away by US Customs due to insects discovered in the packing/pallet materials. Additionally, the reshipment was delayed due to a political situation in Turkey at that time. Ultimately, the 1030 steel was reshipped and received by SFP works. It was discovered that 1040 steel sheet was unavailable at that time and was dropped from the study.

Table I - Steel sheet flash processed: Alloy, weight \% carbon (per supplier), thicknesses and relative temperature difference of the alloy surface with and without the copper rollers.

\begin{tabular}{llllllll}
$\begin{array}{l}\text { Nominal } \\
\text { AISI }\end{array}$ & $\begin{array}{l}\text { Specific } \\
\text { AISI }\end{array}$ & wt $\%$ C & $\begin{array}{l}\text { As-Rec'd Thickness } \\
\text { (in) }\end{array}$ & $\begin{array}{l}\Delta \mathrm{T}\left({ }^{\circ} \mathrm{C}\right) \\
\text { w/o } \\
\text { Copper roller }\end{array}$ & Label \\
\hline 1010 & 1010 & 0.1 & 0.032 & 0.81 & & 220 & 10AR03 \\
& 1010 & 0.1 & 0.09 & 2.3 & & & 10AR09 \\
& 1012 & 0.12 & 0.062 & 1.6 & 100 & & 2AR06 \\
1020 & 1020 & 0.2 & 0.04 & 1.0 & & & 20AR04 \\
& 1020 & 0.2 & 0.078 & 2.0 & 100 & 400 & 23AR05 \\
& 1023 & 0.23 & 0.050 & 1.3 & 110 & 290 & 30AR04 \\
1030 & 1030 & 0.3 & 0.040 & 1.0 & & 120 & 30AR08
\end{tabular}

\subsection{TASK 3: THERMAL MEASUREMENTS AND FLASH PROCESSING}

The flash process is schematically shown in Figure 1. The steel sheet that flows top to bottom through the rollers is induction heated/"flashed". The peak "flash" processing temperature can be varied from $\sim 1000^{\circ} \mathrm{C}$ to $1300^{\circ} \mathrm{C}$, and the time to reach peak temperature can be varied between 2 to 6 seconds. The steel is then water quenched 1 to 3 seconds after heating. Immediately after quenching the sheet progresses through pinch rollers to maintain positive control of the sheet. An example of flashed sheet is shown in Figure 2. Both an IR camera and Pyrolaser pyrometer measured the surface temperature and surface temperature \& emissivity, respectively, of the flashed steel. Table I lists the first set of steel alloys measured for temperature distribution.

Measurement of the temperature and its distribution were challenging; Figure 3 shows a close up of the flash processing setup. Unfortunately, a "steam effect" mostly interfered with the measurements. This steam originated from the boiling and bubbling of the quenching water near the contact regions between the hot steel sheet and cooling water jets. This steam also rose and condensed on the copper induction coils above. Thus, condensed water dripped down forming an additional "waterfall" effect. The micro bolometer IR camera could not make accurate measurements through the steam nor cooling water because they do not transmit light in the 8-12 $\mu \mathrm{m}$ wavelength range. Thus, they appear opaque. 

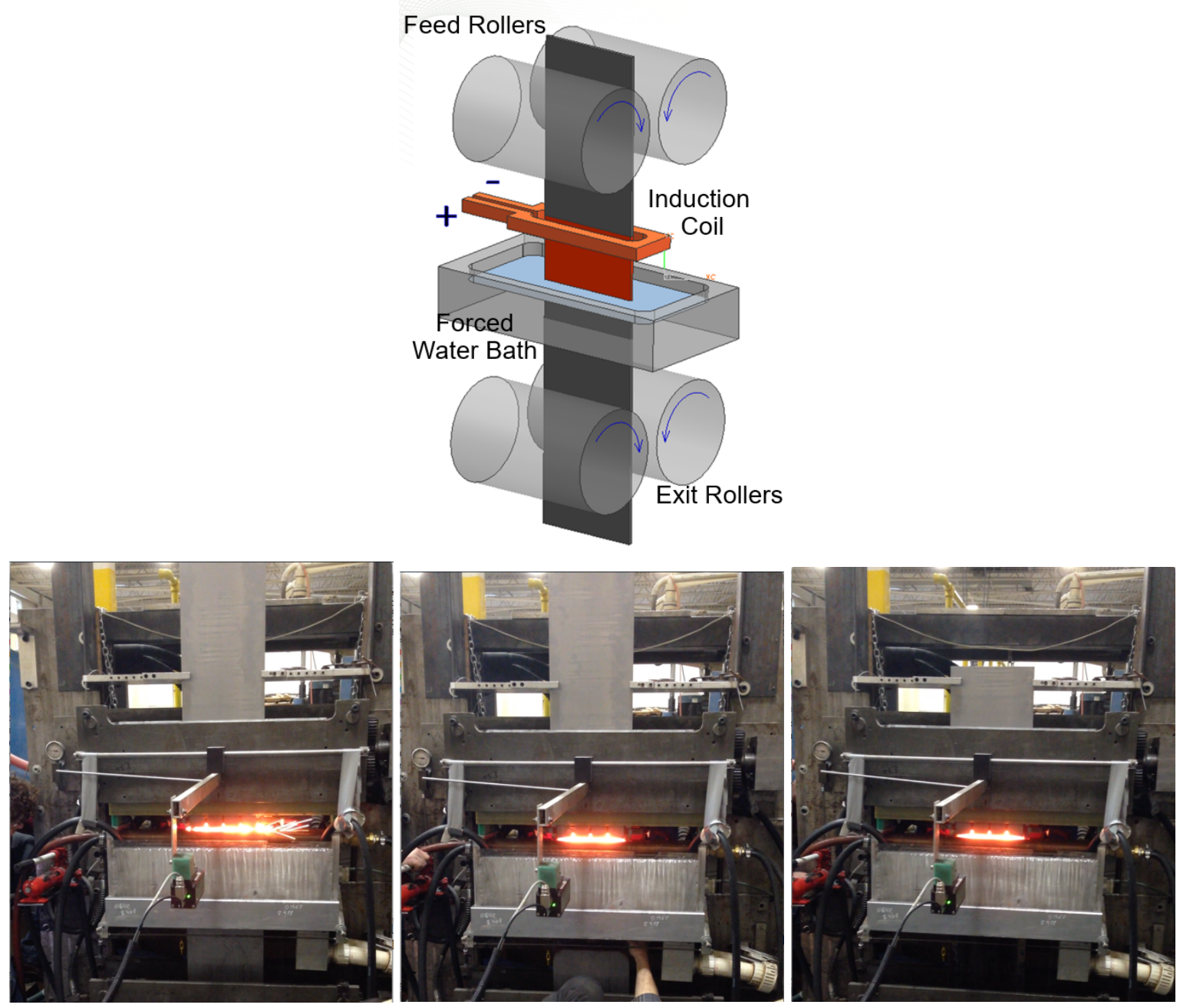

Figure 1- Top: Schematic of the flash process [After Forrest et. al 2017]. Bottom: Excerpts from a movie of the flash process. The feed rate can vary from $1.5-4 \mathrm{ft} / \mathrm{min}$. An optical pyrometer is shown level with the hot zone but appearing in front of the water quenching.

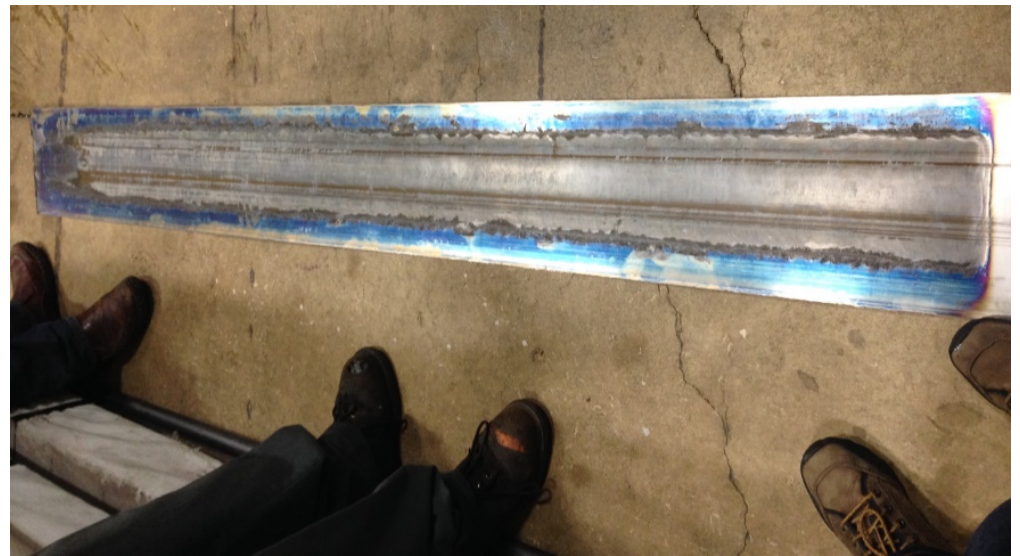

Figure 2 - The product of the flash processing demo of an unknown steel sheet. Note processing of outside edges were not optimized. 


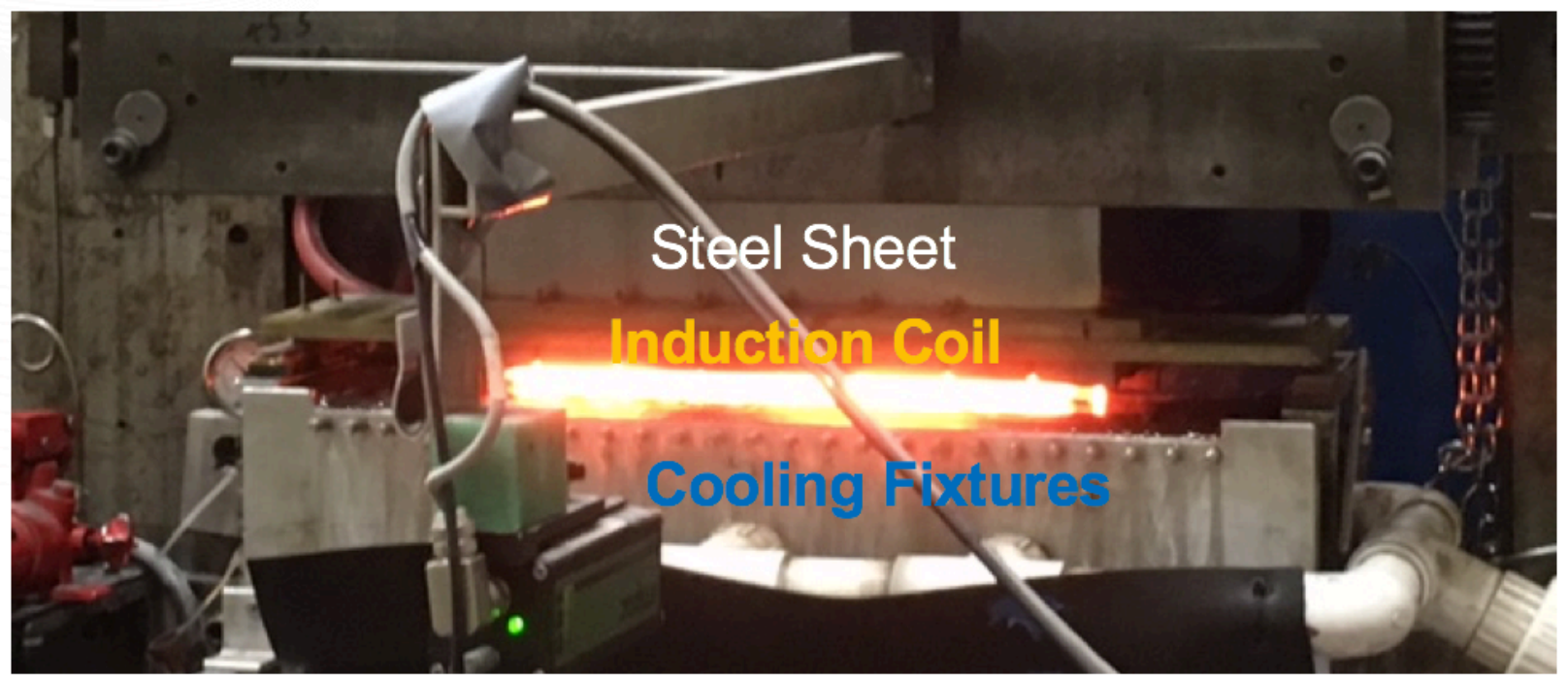

Figure 3 - The steel sheet is being fed from above and passes through the induction coils. The white hot steel is quenched by upwardly squirting water jets. An optical pyrometer with green LED illuminated (not the IR camera) is in the left foreground.
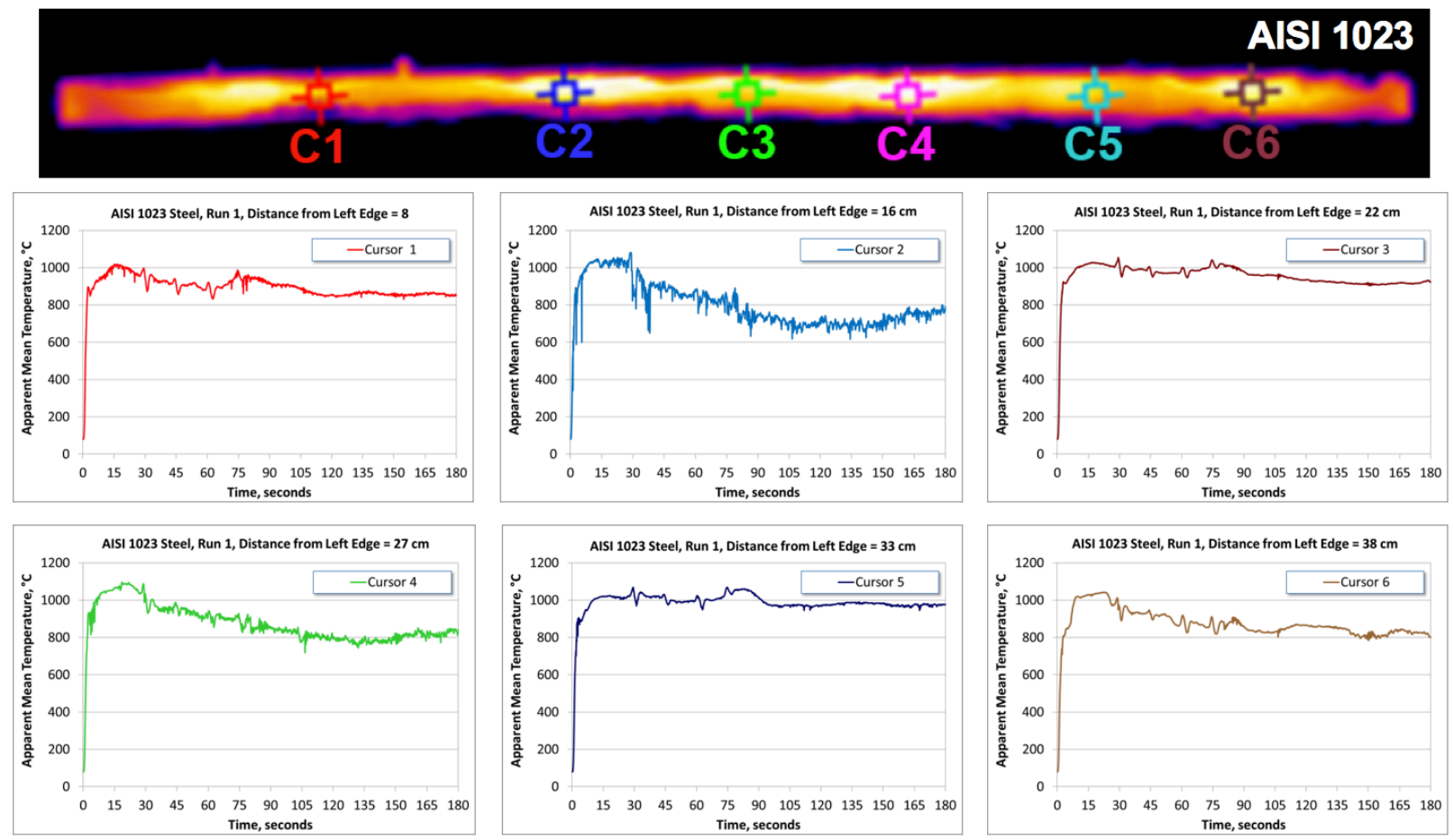

Figure 4 - (Top) The isolated measurement region where the temperature was measured in six locations (C1-C6). The temperature variation at a fixed location/distance from the left edge as a function of time (corresponding to distance along the sheet) is shown for the AISI 1023 steel sheet. 
However, "pockets" or regions along the width of the scanned slot were momentarily clear of the varied water and steam effects, allowing thermal measurement. In Figure 4 at location $\mathrm{C} 2$, the temperature varied from $\sim 1050$ to $\sim 650^{\circ} \mathrm{C}$ along the length of the flashed 1023 sheet. In an effort to mitigate the IR opacity of the water, a "continuous max filter" was developed (e.g., see bottom of Figure 5) wherein the IR image showed the maximum temperature reached by each pixel during the entire 3 minute flash processing treatment. While this filter greatly reduced the influence of the dripping water, it is important to point out certain areas that had heavier water or steam presence than other areas and, in some cases, constant water presence. The "max filtered" images could still have measured much lower temperatures than the actual surface temperatures. In Figure 5, the maximum temperature difference across the plate was $\sim 110^{\circ} \mathrm{C}$, which assumed a constant emittance of 0.79 and ignored the signal from the outer $4 \mathrm{~cm}$ at the edges. In an effort to mitigate the observed temperature non-uniformity of the dripping water, a second set of thermal measurements were conducted with cooled copper rollers (see Figure 6). With the same caveats given above, the maximum measured temperature difference across the copper rolled AISI 1023 sheet was $\sim 400^{\circ} \mathrm{C}$. In Table I, the maximum measured temperature difference is listed suggesting that the temperature difference increased with the use of copper rollers and thinner sheet.

Although the IR camera was not getting a clear view of the surface due to the water, the temperature variations on the surface were reflected in the visible banding across the sheet (see the top portions of Figures 5 and 6). While the application of the cooper rollers appeared to leave the number of bands unchanged, the bands were widened and narrowed alternatively (see Figure 6). These bands (and corresponding non-uniform temperature distribution) are believed to be related to both the spacing of the single-turn induction coils with magnetic concentrators and the altered applied magnetic field.

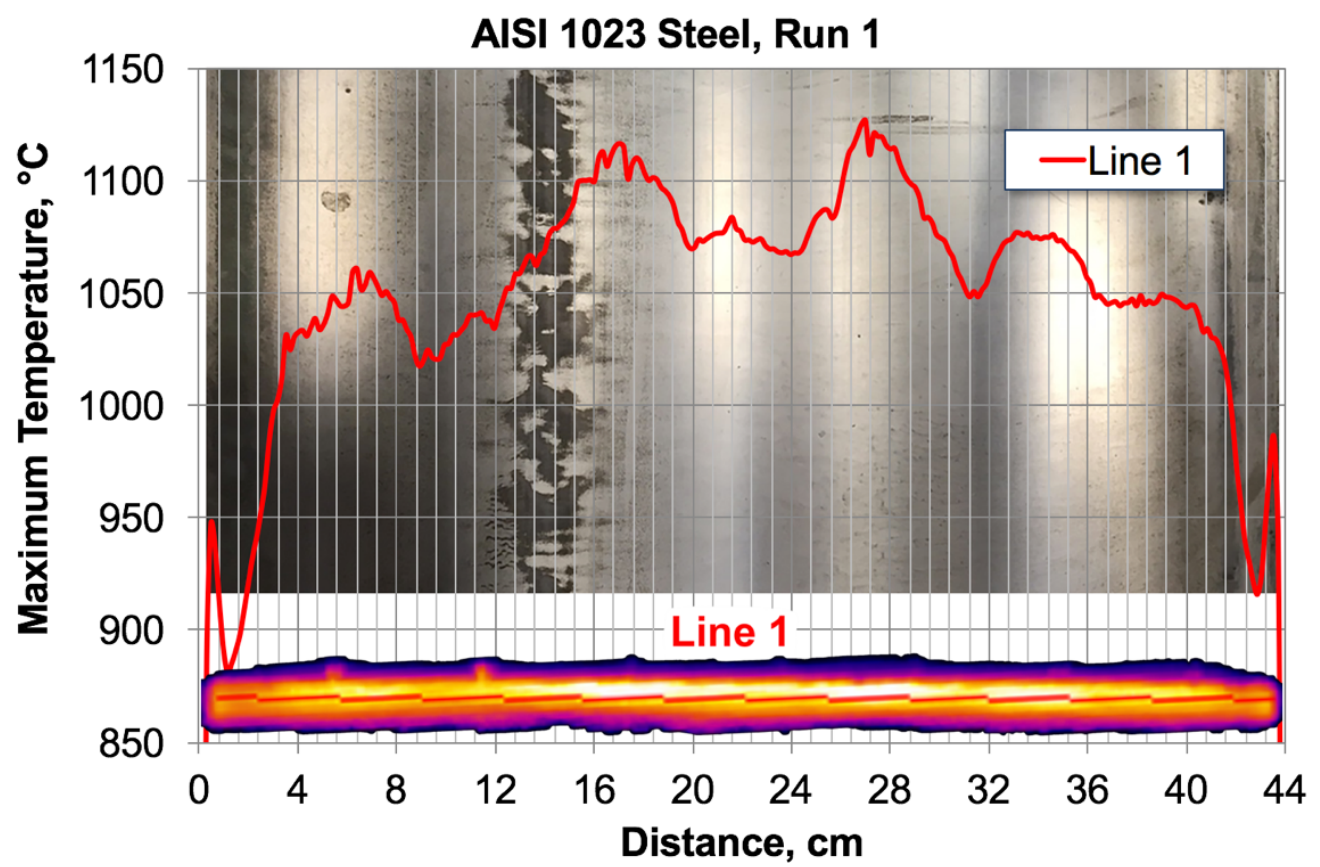

Figure 5 - (Top) The temperature profile as recoded using the "continuous max filter". (Bottom) A visual image of the maximum temperature reached by each pixel during the entire 3 minute flash/heat treatment of the AISI 1023 steel sheet using the "continuous max filter." The banding seen on the sheet originates from the flash process; its origin was not investigated. 


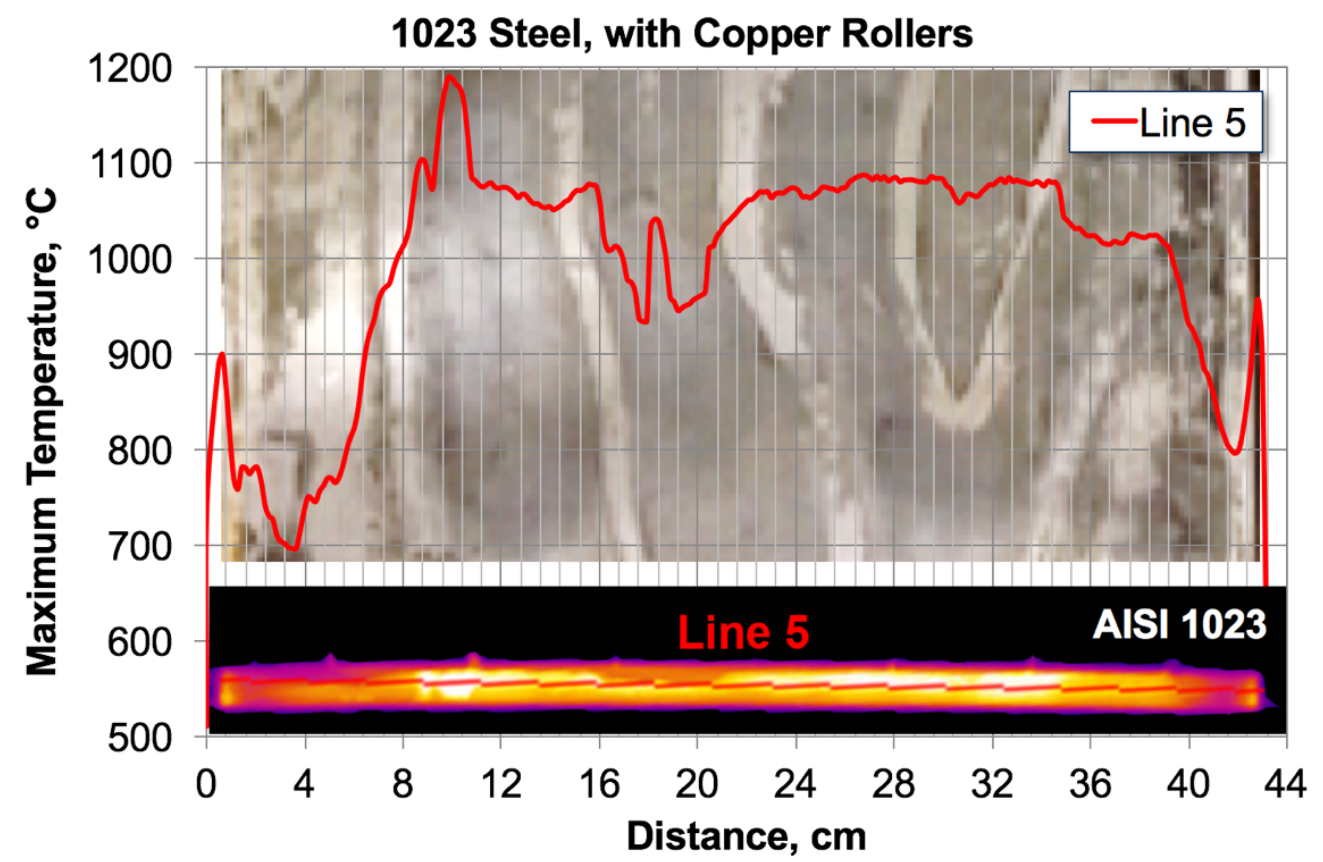

Figure 6 - (Top) The temperature profile as recoded using the "continuous max filter" of the AISI 1023 steel sheet cooled with copper rollers. (Bottom) A corresponding visual image of the maximum temperature reached by each pixel during the entire 3 minute flash/heat treatment using the "continuous max filter."

In a second attempt to measure the temperature distribution across the flashed steel sheet, three runs were made when the gap between the induction coil and cooling water pool was doubled (see Figure 7) and the IR camera was strapped under the existing pyrometer for the system. The Pyrolaser was placed behind the IR camera and captured snapshots, measuring both the surface temperature and emissivity. Figure 8 provides two snapshots clearly indicating that the induction heating was not uniform with temperature differences $>100^{\circ} \mathrm{C}$ perpendicular and parallel to the sheet travel direction. After the third run in this configuration, at least one intensifier was damaged (see Figure 9). Here, the large gap needed for better imaging allowed the steel sheet to warp and touch the intensifier block during the flash processing. Since the intensifier is water cooled and the sheet surface temperature was $>1000^{\circ} \mathrm{C}$, thermal shock likely caused the damage to the intensifier block. Consequently, the non-uniform temperature was even more obvious for the $3^{\text {rd }}$ run. Due to the surface non-uniformity and large temperature variations, the Pyrolaser readings were very inconsistent. The raw intensities and temperature distributions were taken a few seconds apart and found to be very different indicating the dynamic nature of the surface temperature (see Figure 10). Since the IR camera was strapped upside down, the images were flipped and compared similarly to Figure 8.

When the gap distance was returned to the normal distance and after changing to a backup induction coil, the same dripping water effect caused by water steam/evaporation from the quenching and condensation to the coil/intensifiers resumed as before. Because the IR camera operates in the 8-12 micron wavelength, water interference again prevented accurate readings from the surface. However, the smaller gap and new coil did produce a visually more uniform temperature distribution.

It was confirmed that the surface temperature of the sheet was dependent upon gap distance, feeding speed, intensifier placement, heating power and cooling water temperature, which could also change with sheet thickness. Therefore, we conclude that the surface temperatures and temperature distribution across the width during the Flash processing could vary due to multiple parameters. In order to have better control of the process and optimize the product properties, simulation of the RF field and subsequent 


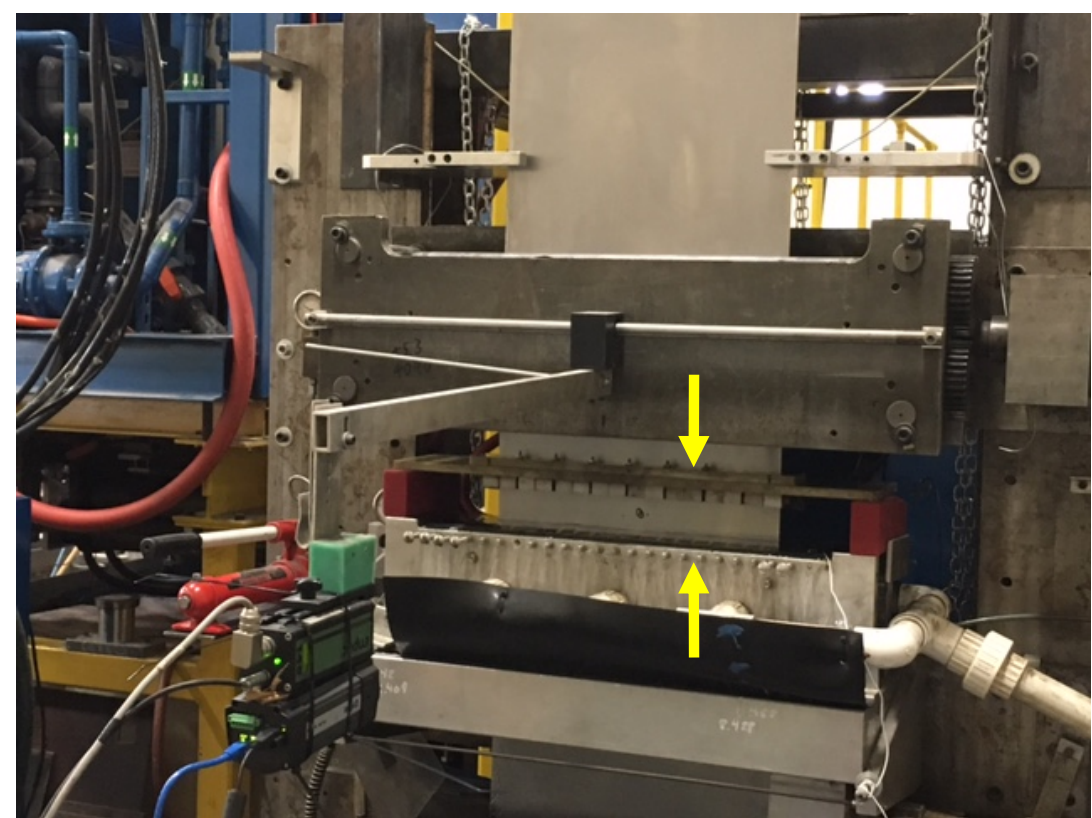

Figure 7. Wider gap (arrows) setup at SFP Works for thermal imaging.

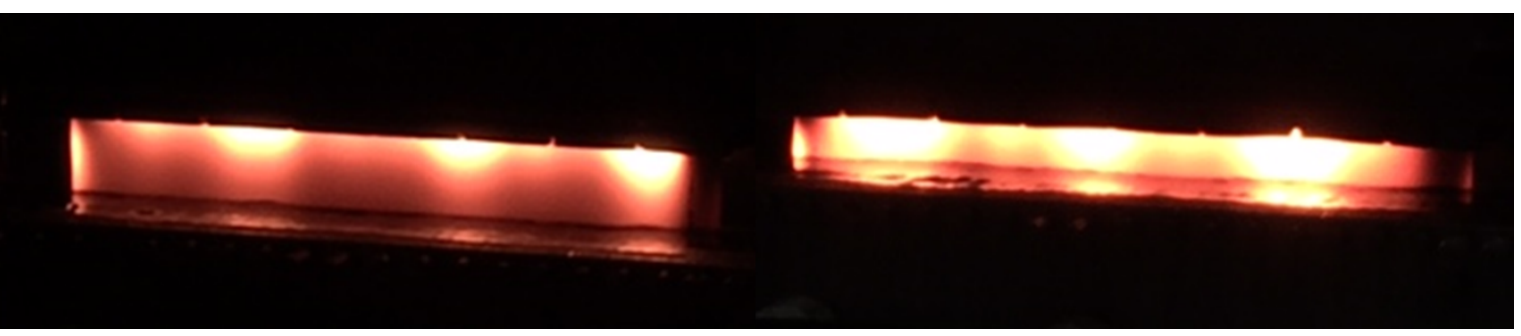

Figure 8. Visible images of the temperature variation/distribution observed during processing.

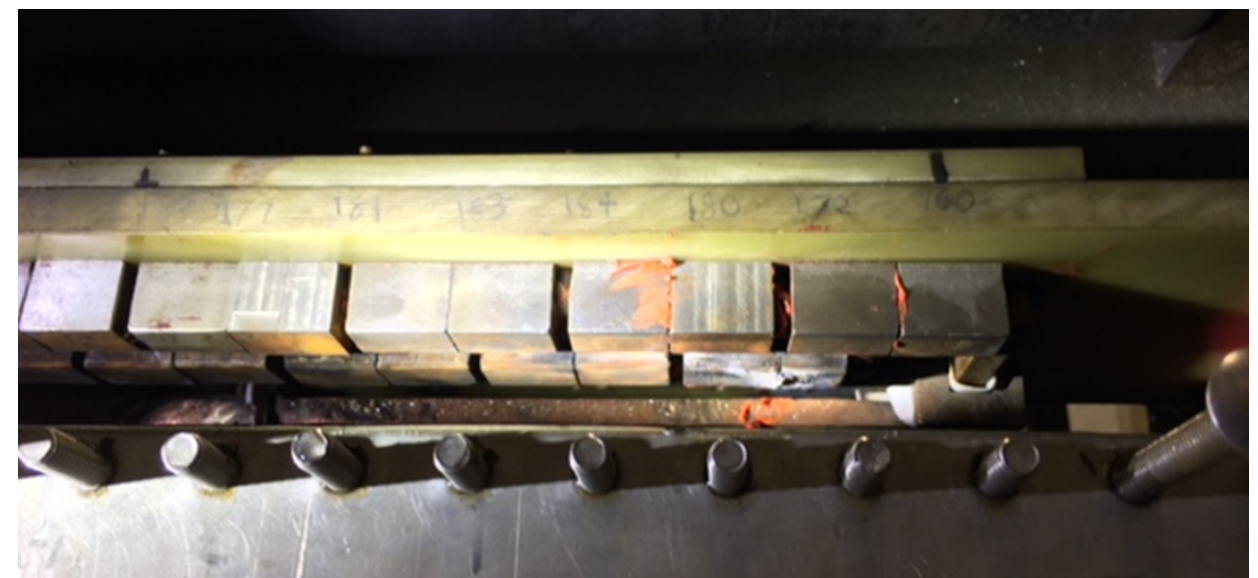

Figure 9. Photo of the induction coil after run \#3 showing damage present on an intensifier block in the back row, right most. 


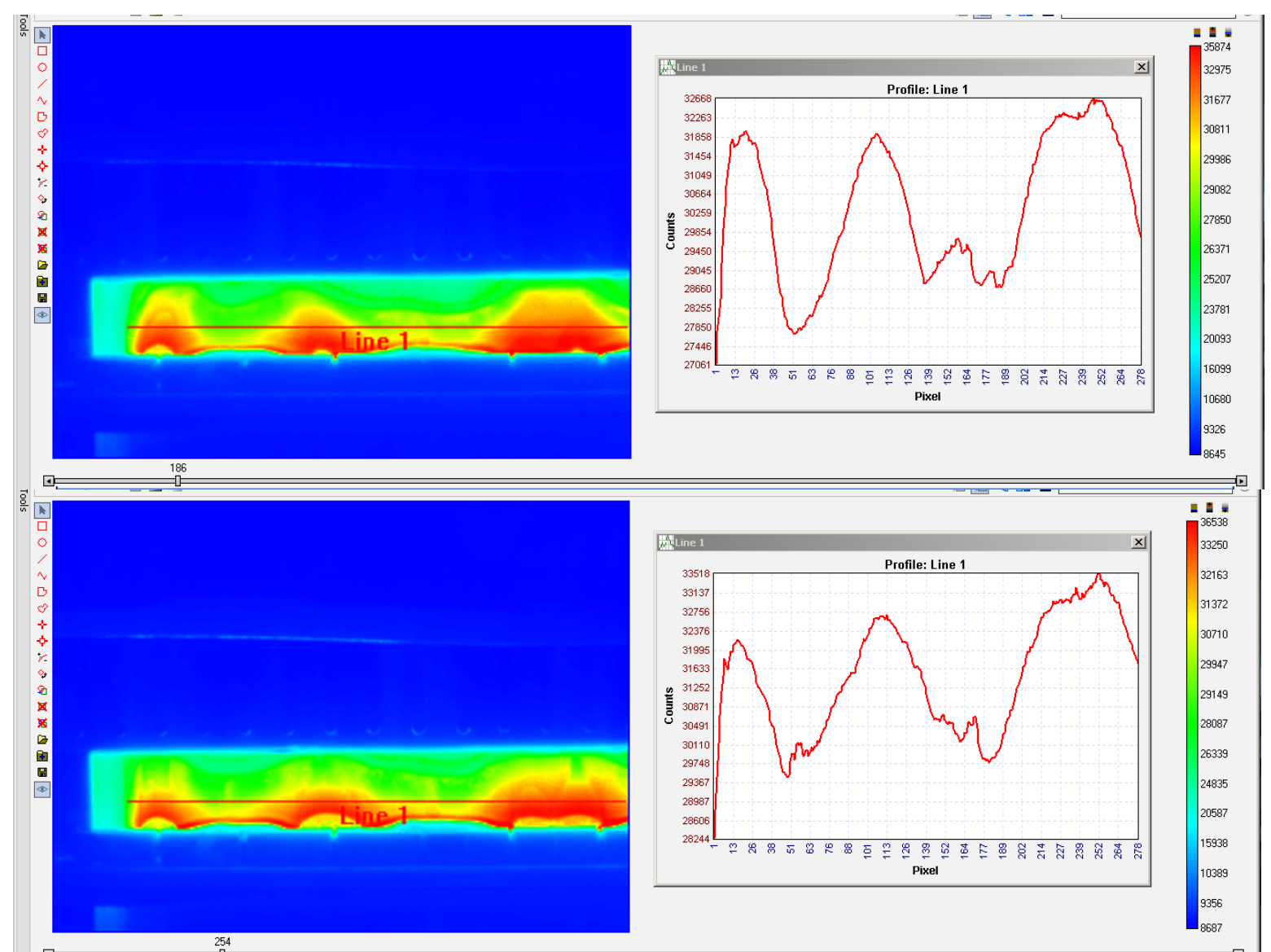

Figure 10. Two screenshots of the IR image analysis showing two infrared plots and temperature line profiles across the 1010 steel sheet width. As raw IR count is displayed in the images and profiles, postanalysis is needed to convert them into actual temperatures.

heating profile may be needed. An open question is whether or not uniform temperature across the sheet width is required as it may be the that temperature gradients provide the microstructure that allows good forming.

\subsection{TASKS 2, 4, 5: CHARACTERIZATIONS AND FORMABILITY LIMITS}

A dome test was adopted as a measure of flashed sheet formability. Figure 11 shows a hydraulic compression/tension frame, set in compression mode, with 100,000 lb. load cell attached. The sample holder clamps down on the circumference of the sample disk, and subsequently, a hemispherical punch (a steel sphere) is pushed up into the disk. Digital Image Correlation (DIC) cameras are angled to image the top of the disk, allowing the measurement of the " $3 \mathrm{D}$ " strain fields of the dome produced by the punch. Parameters such as dome height and major \& minor Lagrangian strain maps were utilized to compare the performance of the as-received and flashed steel sheets. To that end, two sets of six, $5.45 \mathrm{in}$. (138.4 mm) diameter disks were cut from the as-received steel sheet. One set was ground to one of two uniform thicknesses, 0.028 or 0.056 in. ( 0.71 or $1.42 \mathrm{~mm}$, respectively), to allow for comparison without thickness variations, while the second set was tested with the as-received thickness. 


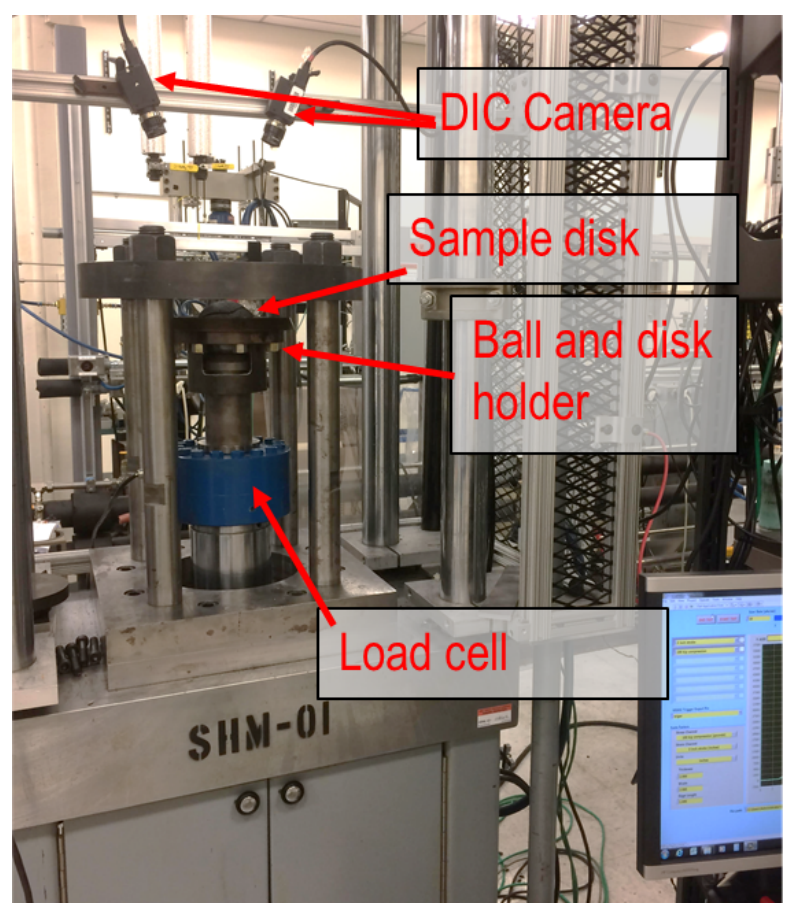

Figure 11. Formability testing apparatus wherein a disk sample is "formed"/bulged to failure. This operation is then similar to deep drawing.

Figure 12a shows a fair bit of variability amongst the dome displacement curves of as-received disks, suggesting the necessity for testing with uniform thickness. Figure $12 \mathrm{~b}$ shows the same data except the load is normalized by the disk thickness, allowing for easier comparison. Note that the outlying blue curve (10AR09) was a disk that slipped in the sample holder due to insufficient clamping at the perimeter. Subsequently, an increased bolt torque was used to hold down the remaining discs. In Figure 12b, the black circles show some potential differences (30AR04). The lower black circle highlights the raw asreceived 1030 steel. The upper black circle shows the results of the same material after a 2 hour anneal at $950{ }^{\circ} \mathrm{C}$ and furnace cool. The low strength and brittle behavior suggest that the as-received 30AR04 material was heavily cold rolled when compared to the annealed. The DIC analysis showed strain localization in a ring $45^{\circ}$ off the dome center axis and is a widely known result in biaxial dome testing, wherein the ring is due to the stretching from deformation.
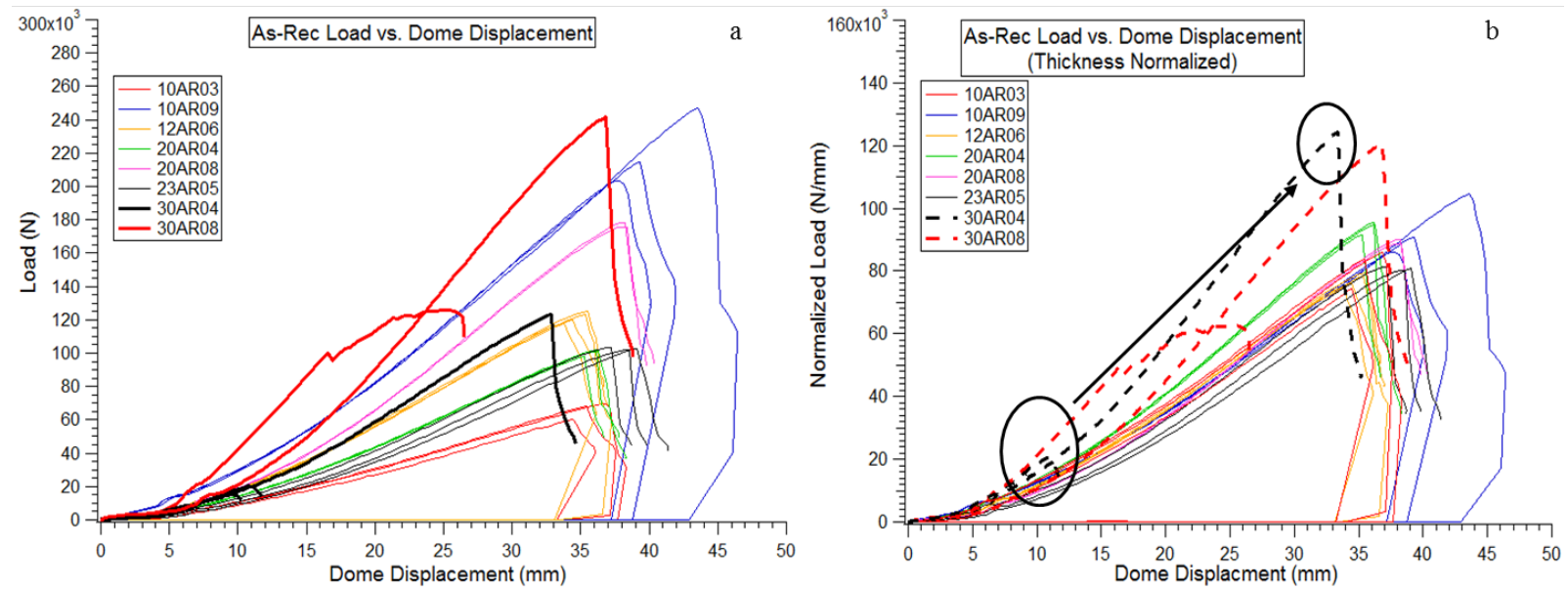

Figure $12 \mathrm{a}$. Load as a function of dome displacement for the as-received samples with varied thicknesses. b. Load normalized by disk thickness as a function of dome displacement. There were three disks tested for each alloy/thickness combination listed in Table I. 
In Figure 13, a comparison of the load, normalized load, and dome displacement are charted against the carbon concentration and sample thickness of the as-received sheets. On the left (labeled "Carbon Concentration Comparison"), this comparison shows that carbon concentration does not affect the performance of the as-received sheets. On the right, the load at failure increases with increasing thickness as expected because there is more material to resist deformation with thicker samples. With normalization for sheet thickness, all the sheets performed similarly. Note, the raw 1030 material is not presented because of the poor properties.

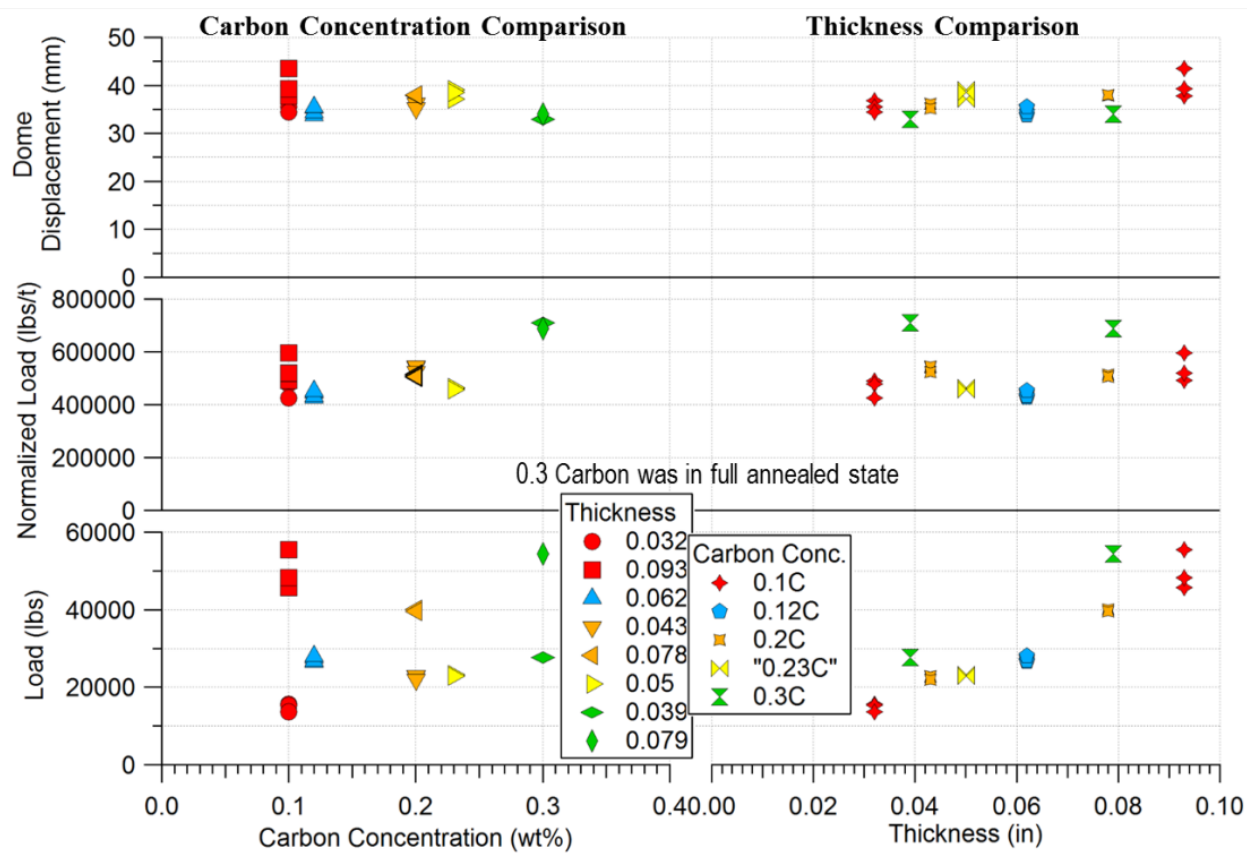

Figure 13. Sheet comparison between bulk carbon concentration (per supplier) and thickness. On the left, the symbol shapes distinguish the different sample thicknesses. On the right, the symbol shapes distinguish the different carbon concentrations. On both sides, the colors indicate the carbon concentration: red $=0.1$, blue $=0.12$, orange $=0.2$, yellow $=0.23$, and green $=0.3$ in wt $\%$ carbon.

Figure 14 shows variable load versus dome displacement curves of un-flashed (as-received) and flashed disks (listed in Table II). The 10AR/FP04 (red lines) samples were brittle and did not form. These samples fractured during the clamp down in the sample holder (see Figure 15A). \{Note that the curves show a dome displacement between $15 \mathrm{~mm}$ to $20 \mathrm{~mm}$, this is an artifact of the compression frame. The compression frame required a manual stop, and the frame was stopped after peak load and not when the first crack was observed. The first crack typically appeared after a dome displacement of approximately $5 \mathrm{~mm}$ to $7 \mathrm{~mm}$ in all cases. \}. The 12AR/FP06 (orange lines) exhibited more formability (see Figure 15B). The un-flashed condition formed to a dome displacement of approximately $30 \mathrm{~mm}$ with a load of $100 \mathrm{x}$

Table II - Flashed Processed steel sheet formability tested: Alloy, weight \% carbon and thicknesses.

\begin{tabular}{|c|c|c|c|c|c|c|}
\hline $\begin{array}{l}\text { Nominal } \\
\text { AISI }\end{array}$ & $\begin{array}{l}\text { Specific } \\
\text { AISI }\end{array}$ & $\mathrm{wt} \% \mathrm{C}$ & $\begin{array}{l}\text { As-Rec } \\
\text { (in) }\end{array}$ & $\begin{array}{l}\text { hickness } \\
(\mathrm{mm})\end{array}$ & $\begin{array}{l}\text { Legend label } \\
\text { As-Received } \\
\text { Un-flashed }\end{array}$ & Flash \\
\hline \multirow[t]{2}{*}{1010} & 1010 & 0.1 & 0.039 & 1.0 & 10AR04 & 10FP04 \\
\hline & 1012 & 0.12 & 0.062 & 1.6 & 12AR06 & $12 \mathrm{FP} 06$ \\
\hline \multirow[t]{2}{*}{1020} & 1020 & 0.2 & 0.078 & 2.0 & & 20FP08 \\
\hline & 1023 & 0.23 & 0.050 & 1.3 & 23AR05 & 23FP05 \\
\hline 1030 & 1030 & 0.3 & 0.040 & 1.0 & 30AR04 & 30FP04 \\
\hline \multicolumn{2}{|c|}{ M1500 Standard } & $\sim 0.2$ & 0.050 & 1.3 & \multicolumn{2}{|c|}{ M1500 (not Flash Processed) } \\
\hline
\end{tabular}




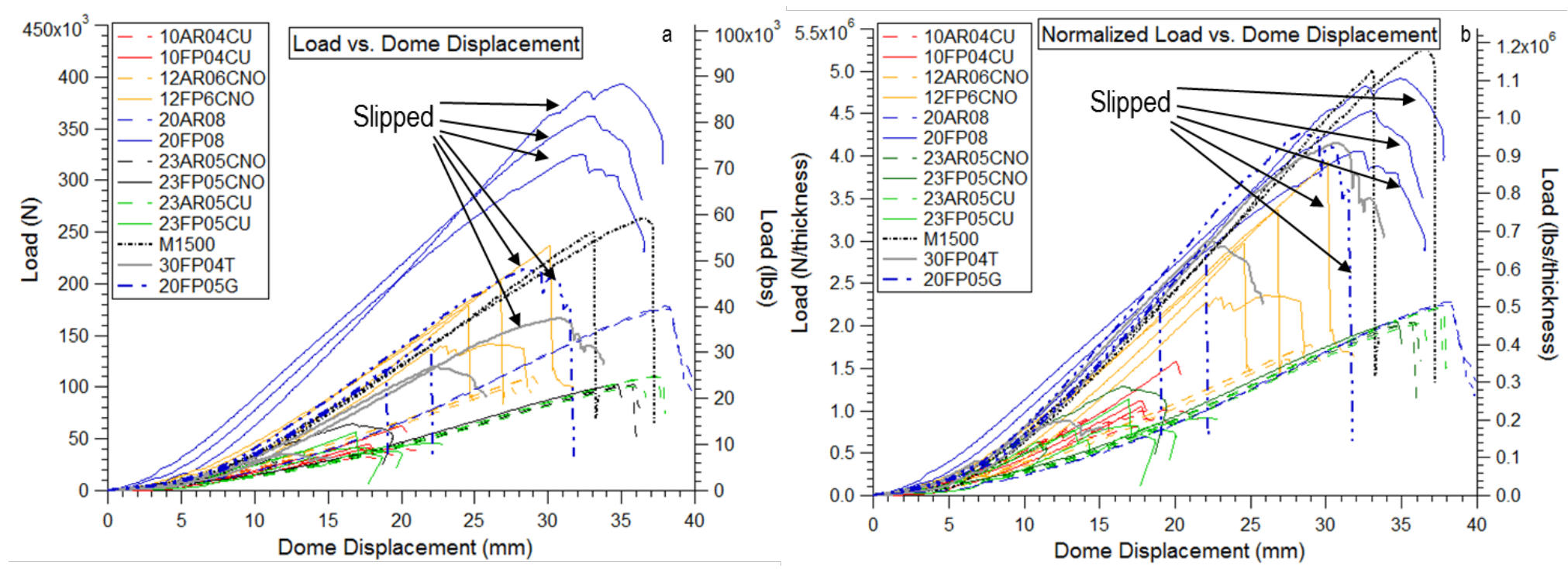

Figure $14 \mathrm{a}$. Load as a function of dome displacement for the as-flashed and un-flashed samples with varied thicknesses. b. Load normalized by disk thickness as a function of dome displacement. A few test disks slipped in the holder, which produced seemingly better properties. (Legend sample name suffixes: $\mathrm{CU}$ indicates copper rollers were used; $\mathrm{CNO}$ indicates copper rollers were not used; $\mathrm{G}$ indicates ground; $\mathrm{T}$ indicated tempering $475^{\circ} \mathrm{C}$ for 10 minutes). The as-received and flashed samples, both from the same sheet, are shown with the same color. The as-received condition is shown with dashed lines, with exception of the M1500 standard and the 20FP05G (which was ground from the 20FP08 sample (0.8in./2mm ground to $0.05 \mathrm{in} . / 1.3 \mathrm{~mm}$ thickness). 

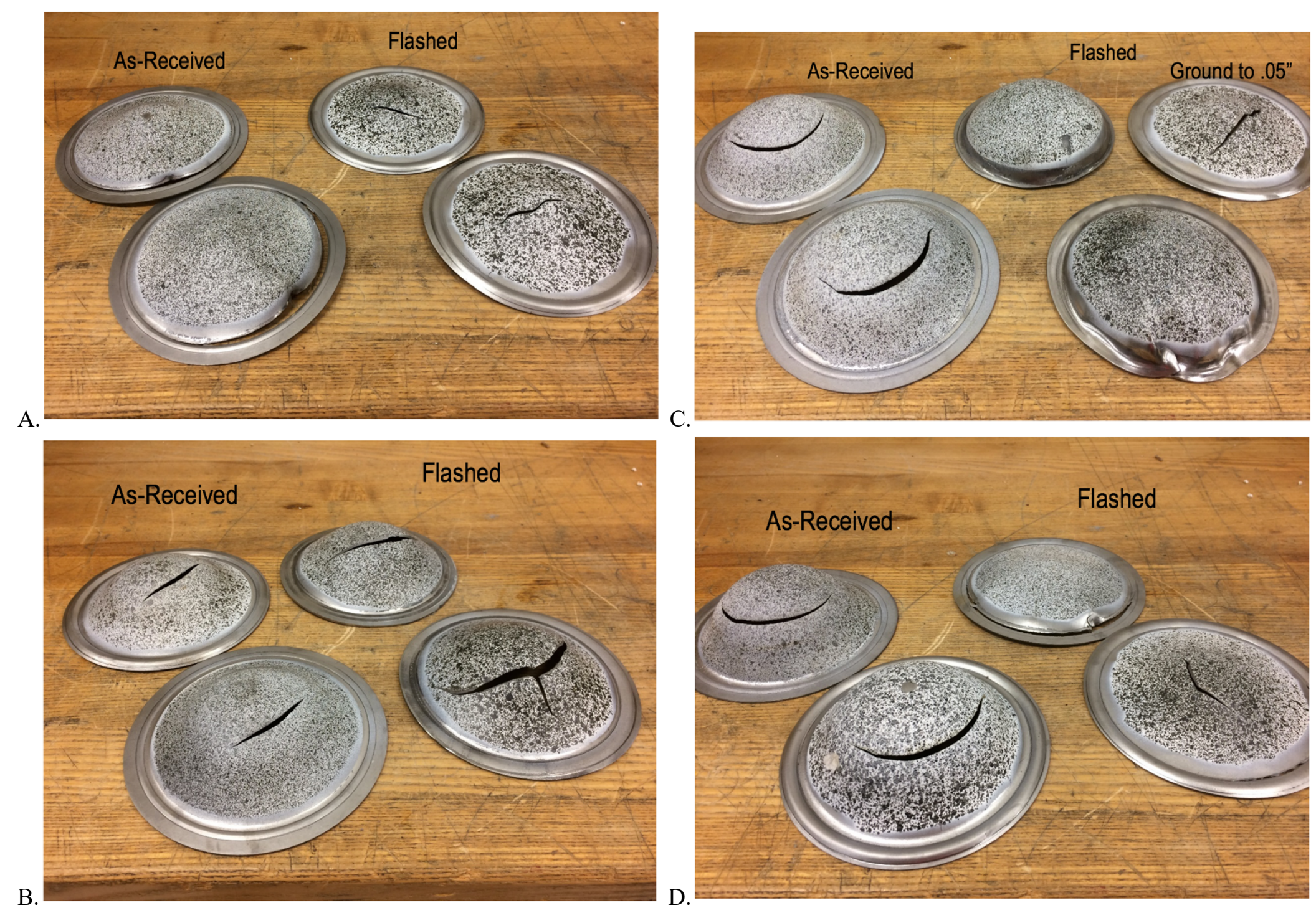

Figure 15 - The domes formed during formability testing. The speckle pattern was sprayed onto the top, which was necessary for the DIC strain measurement technique: A. 10AR04 \& 10FP04, B. 12AR06 \& 12FP06, C. 20AR08, 20FP08 \& 20FP05G and D. 23 AR05 \& 23FP05. 
$10^{3} \mathrm{~N}$. On the other hand, the flashed condition was able to form to $23 \mathrm{~mm}$ to $27 \mathrm{~mm}$ with a load of approximately $200 \times 10^{3} \mathrm{~N}$. One sample did form to $>30 \mathrm{~mm}$ and $>200 \times 10^{3} \mathrm{~N}$, however this sample slipped in the sample holder which did not provide a true biaxial dome displacement. However, even with thickness normalization, this sample underperformed the M1500 (commercially available $1500 \mathrm{MPa}$ UTS martensitic steel standard). While the 20FP08 sample set did produce a large dome displacement (30 mm to $35 \mathrm{~mm}$ ), this set of samples was too thick for the sample clamp holder, and all samples slipped in the clamping ring. The slipping allowed for dome displacement without straining, invalidating the test. Even with thickness normalization the 20FP08 sample set slightly under performed relative to the M1500.

Because of this challenge, three disks of the $20 \mathrm{FP} 08$ sheet were ground to $0.05 \mathrm{in} . / 1.3 \mathrm{~mm}$, the same as M1500. These are represented in Figure 14 with the blue dashed lines (also see Figure 15C). One of samples still slipped giving a large dome displacement. Two disks did not slip and showed poor properties, $19 \mathrm{~mm}$ to $22 \mathrm{~mm}$ dome displacement with a load of 100 to $130 \times 10^{3} \mathrm{~N}$. However, it should be noted that grinding the disks may have removed some or all of the microstructural parameters which aid in the formability. The 23AR05 (as-received) sample set did form as expected in the un-flashed condition. The flashed condition was brittle and failed very early in the test (see Figure 15D). Similarly, the 30FP04 samples also failed early, although one sample did slip, again showing the effects of slipping.

The DIC analysis did not show any differences between the as-received/un-flashed conditions and flash processed conditions, although the as-expected strain localization at the $45^{\circ}$ concentric ring around the dome was observed. Also, the brittle samples did not show any strain localization before fracture. As such, the DIC work was discontinued.

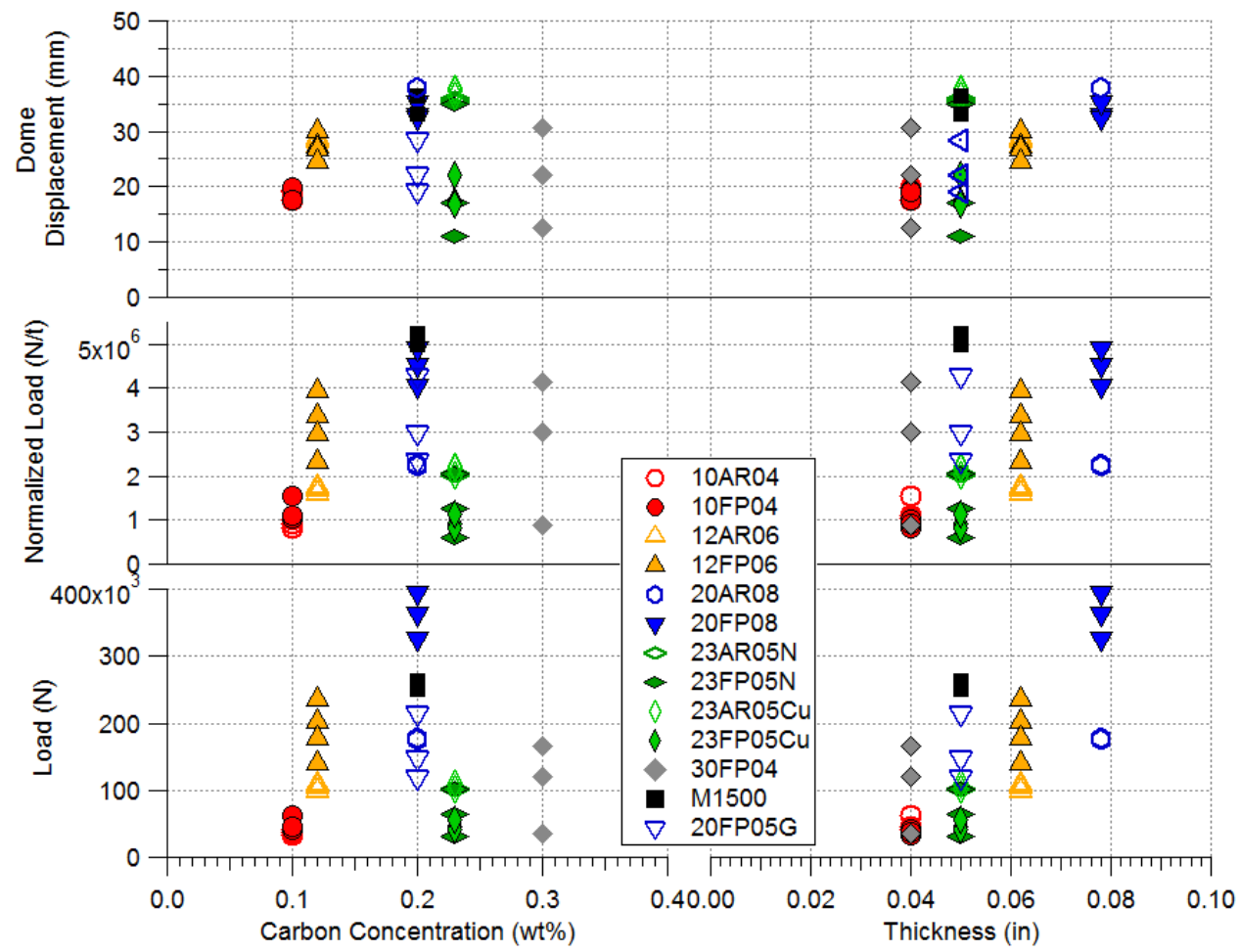

Figure 16 - Sheet comparison between bulk carbon concentration (per supplier) (left) and thickness (right). The symbol shapes and color represent samples from a single sheet, open shapes are asreceived/un-flashed and solid shapes are flashed. 
In Figure 16, the load, normalized load, and dome displacement are plotted against the carbon concentration and sample thickness of the as-received/un-flashed and flashed sheets. On the left, the deformation as a function of carbon concentration is not linear for the as-received and flashed sheets. On the right, the load at failure increases with increasing thickness, as expected. With normalization, however, the sample performances are not consistent.

Based on earlier dome testing, the formability of the flash processed sheet is thought/hypothesized to be derived from a through thickness microstructural variation: a hard layer sandwiched in between two softer layers of steel. As such, samples (12 mm x $12 \mathrm{~mm}$ ) were extracted from both as-received AISI 1020, Flash Processed AISI 1020, and M1500 (a commercially available alloy with $1500 \mathrm{MPa}$ UTS) sheets, each of which had favorable dome test. Each sample was mounted in a metallographic mount such that the "thickness - rolling direction" plane of the samples was polished for nano hardness analysis. A nanoindenter was used to construct a hardness map of the through thickness microstructure; thousands of individual indents were performed, each at a load of $300 \mathrm{~g}$.

The as-received AISI 1020 steel sheet is commonly hot rolled and annealed material with a thickness of 0.08 in $(2 \mathrm{~mm})$. In Figures 17A and 18A, a representative hardness map and a histogram of the hardness values of the as-received AISI 1020 sheet are shown, respectively. The as-received condition did not show any hardness heterogeneity, except near the bottom edge. Thus, the distribution of hardness is bimodal with the average hardness for the majority of the cross-section being $132 \pm 10 \mathrm{HVN}$. The soft edge had an average hardness of $110 \pm 10 \mathrm{HVN}$.

In contrast in Figures 17B and 18B, show a hardness map and a histogram of the flash-processed AISI 1020 sheet sample, showing a significant hardness heterogeneity across the $\sim 2 \mathrm{~mm}$ thick cross-section. Locally hard and soft areas are present through the thickness. The distribution of hardness values is 100 HVN, with an average hardness of roughly $480 \mathrm{HVN}$. This hardness profile indicates microstructural heterogeneity with (simplistically) the center being harder than the edges. The microstructure of the Flash Processed sample is martensite and was expected to have a higher hardness than the annealed ferritic microstructure of the as-received material. The current hypothesis of the mechanism causing the heterogeneity is segregation of carbon within the austenite during Flash Processing; literature has demonstrated that microstructural heterogeneity can be beneficial to mechanical properties, such as formability.[Gan et al., 2006] 


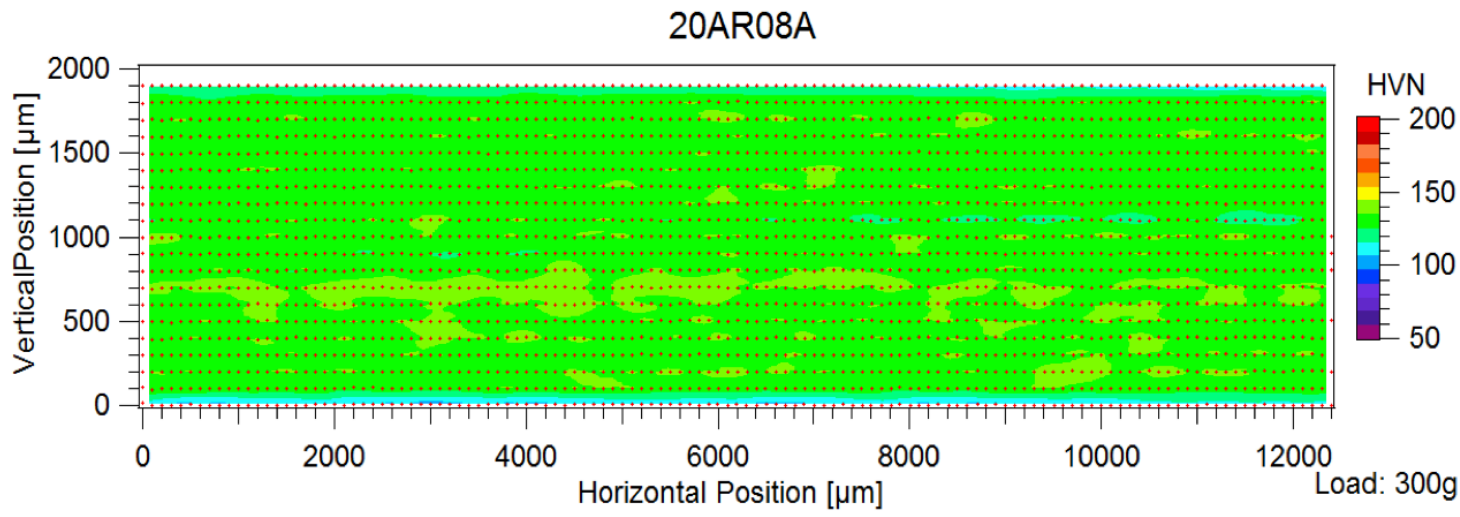

A.

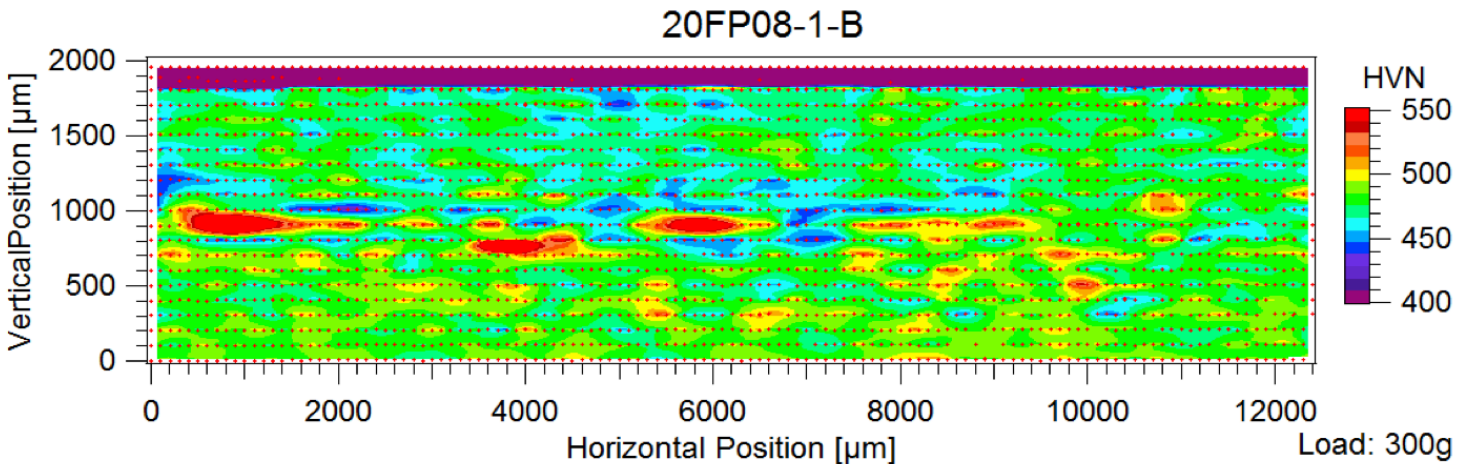

B.

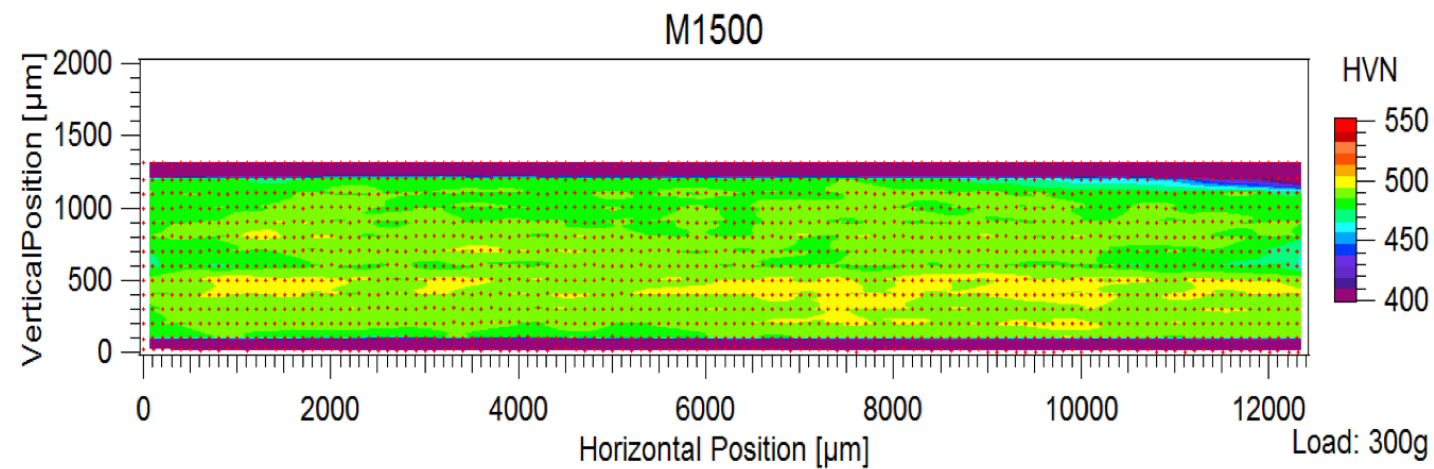

C.

Figure 17 - The hardness profiles for A. as-received AISI 1020, B. flash processed AISI 1020, and C. asreceived M1500 steel. Note the purple bands reflect the hardness of the mounting epoxy. The color scales in all range $150 \mathrm{HVN}$ with each color representing a 9.3 VHN difference. 


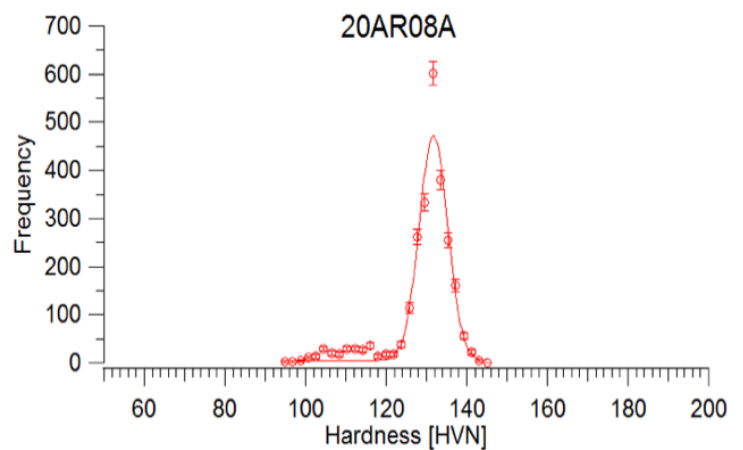

A.
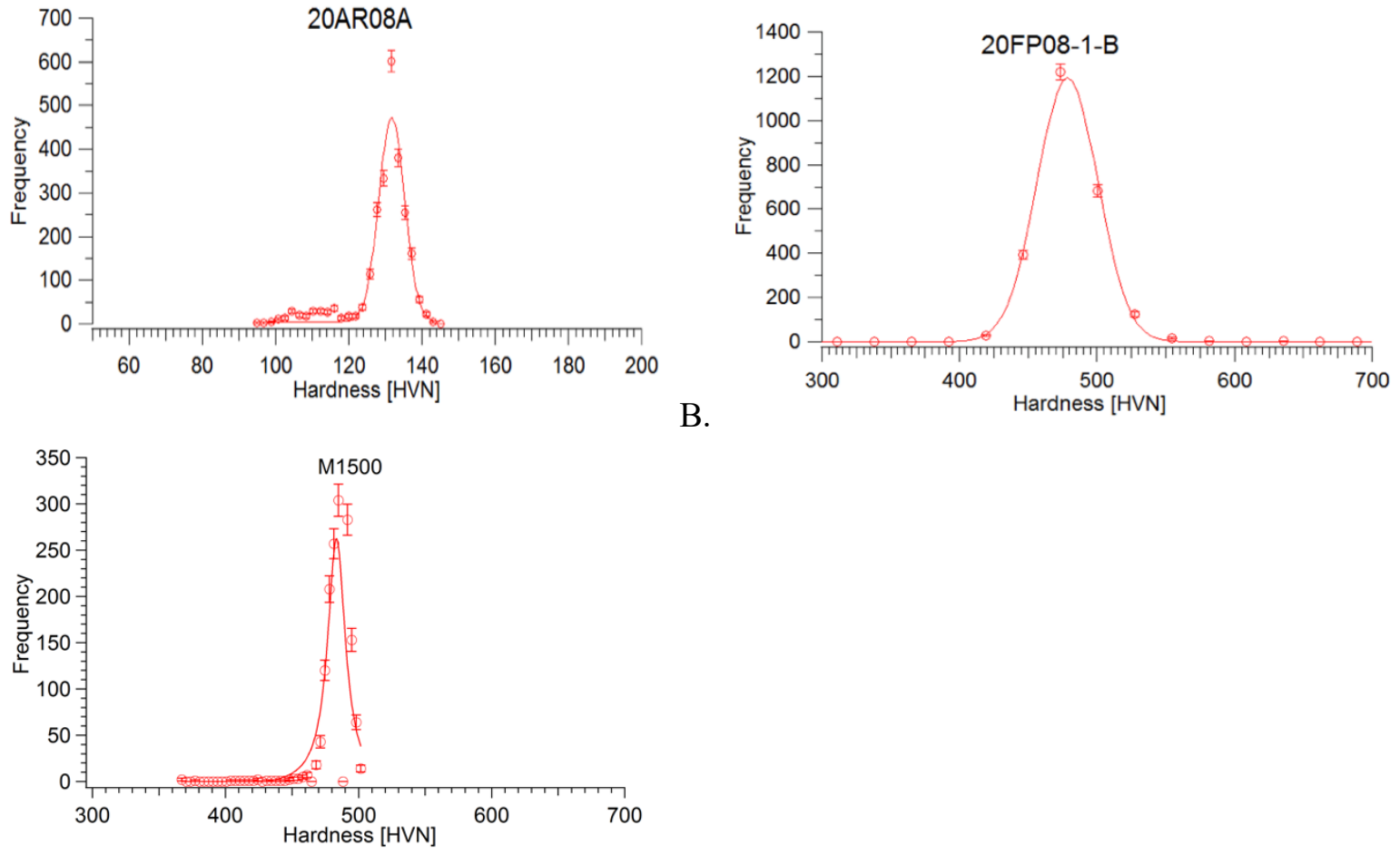

B.

C.

Figure 18 - The histograms of the hardness profiles from Figure 1 for A. as-received AISI 1020, B. flash processed AISI 1020, and C. as-received M1500 steel.

In Figures $17 \mathrm{C}$ and $18 \mathrm{C}$, a representative hardness map across the $0.06 \mathrm{in} .(1.5 \mathrm{~mm})$ thick cross-section and a histogram of the hardness values of the as-received M1500 sheet are shown. The M1500 product is carefully processed to produce homogeneity to reduce scatter of mechanical properties in large rolls. As such, the hardness map shows only a slight through thickness distribution of hardness, and the histogram confirms this result. Although not entirely shown, the distribution of hardness values is less than $25 \mathrm{HVN}$ with the average of $490 \mathrm{HVN}$.

Given the lack of forming, as represented by the dome testing, of this first set of samples, further characterization efforts were abandoned in favor of flash processing another smaller subset of samples (see below).

\section{A Second Set of Flash Processed Samples}

For flash processing, the expected "processing window" for good formability will depend upon alloy composition (i.e. carbon content) and thickness with specific microstructural distributions through thickness. The results above suggest that the current flash processing parameters may not be within the optimum processing window to produce a formable product. Consequently, another 0.05 in. $(1.3 \mathrm{~mm})$ thick sheet of 1023 steel was processed at four target temperatures $\left(1070{ }^{\circ} \mathrm{C}, 1140{ }^{\circ} \mathrm{C}, 1170{ }^{\circ} \mathrm{C}\right.$, and 1270 ${ }^{\circ} \mathrm{C}$ ). Formability (i.e., dome displacement) testing was performed after processing. Since the "normal" flash processing temperature for 1023 sheet is around $1140{ }^{\circ} \mathrm{C}$, temperatures were chosen above and below the "normal". The temperature was measured by the in-house single color pyrometer (see in Figures 1, 3 and 7), measured at the center of the width of the sheet. After the initial $15 \mathrm{in}$. (380 mm) of travel, the power was increased to obtain the second temperature. This was repeated until all four temperatures were obtained. 
Figure 19 shows the load versus dome displacement curves. All the samples flash processed at $1070{ }^{\circ} \mathrm{C}$ and $1140{ }^{\circ} \mathrm{C}$ cracked along the circumference at the hold down ring when tightening the bolts of the disk clamp. The crack did not traverse the entire circumference $(\sim 50 \%-75 \%)$. The cracked samples were still tested with some initial loading still observed. However, the preexisting circumferential cracks led to premature failure (note jagged features in Figure 19). However, one sample from each of the $1170{ }^{\circ} \mathrm{C}$ and $1270{ }^{\circ} \mathrm{C}$ samples maintained integrity in the disk holder and gave a successful test result (i.e., no slipping on the disk holder and no cracking due to clamping). Both successful disks came from the middle of the sheet with the failure locations for both at the apex of the dome. While the sample disks extracted from the side of the sheet cracked during clamping, the cracking only occurred in the regions which were within 2 inches of either edge of the sheet. Note, this was different from the lower temperature samples where all the samples cracked along the entire circumference.

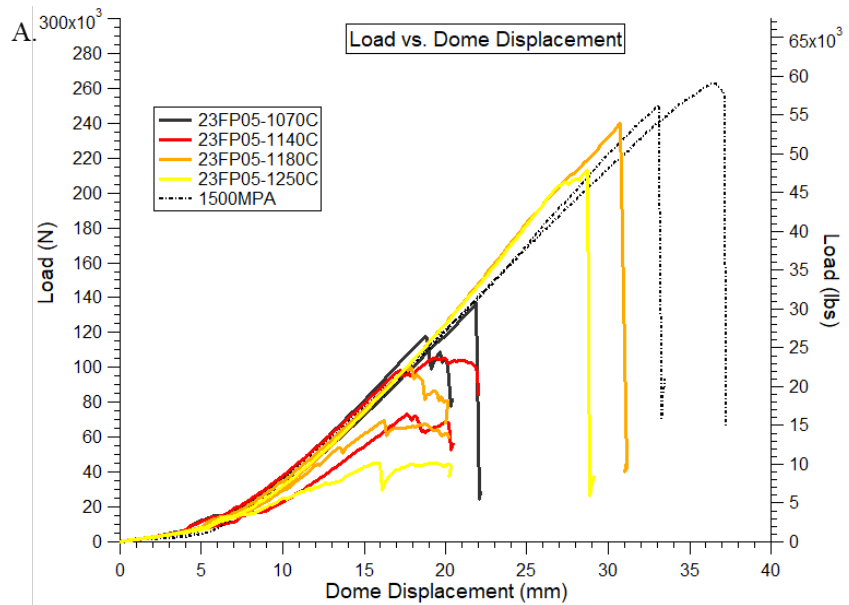

Figure 19 - A. Load versus dome displacement of the 1023 steel sheet with varying flash temperatures. The curves for as-received M1500 have been added for comparison.

Figure 20 shows the through thickness hardness profiles from samples flashed at three different temperatures. The $1070{ }^{\circ} \mathrm{C}$ temperature sample displays the most uniform hardness profile. The lack of the soft exterior with harder center line region, within microstructures after flash processing, suggests that the sample will not form [Lolla et al. 2013]. The hardness band is also absent in the hardness profile from the $1170{ }^{\circ} \mathrm{C}$ sample, which formed well. However, because of sample limitations, the location of the1170 ${ }^{\circ} \mathrm{C}$ sample for hardness testing originated 1 to 2 inches away from the area where the disk used in the forming test was extracted. Not surprisingly, spatial differences should be expected to show variations from flash processing due to inhomogeneous temperatures across the width of the sheet. Spatial variations themselves may play an important role in the central hardness band. The $1270{ }^{\circ} \mathrm{C}$ hardness sample, however, was taken close to the location where the disk that formed was extracted and does show the typical hardness band. This could be an indication of the correlation between formability and microstructure.

Figure 21 shows the histograms of the hardness maps from Figure 20. The averages of all the samples are roughly 500-510 HVN. The spread of hardness values for all the samples is about $100 \mathrm{HVN}$ and is consistent with previous examples of hardness profiles from flash processing. The presence or absence of a hardness band also does not seem to affect the average hardness. However, a small bimodal distribution of higher hardness values may be observed in the $1270{ }^{\circ} \mathrm{C}$ sample, representing the hardness band (see Fig 20C) in the center of the cross-section. This supports the hypothesis that the central hardness band correlates to the formability of flashed processed steel. Figure 22 shows the SEM and electron 


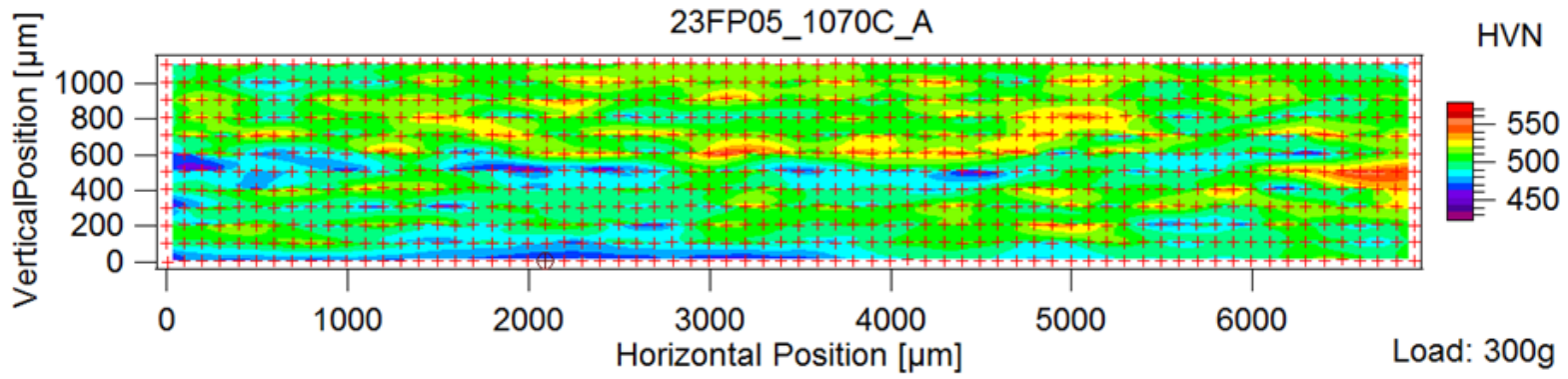

A.

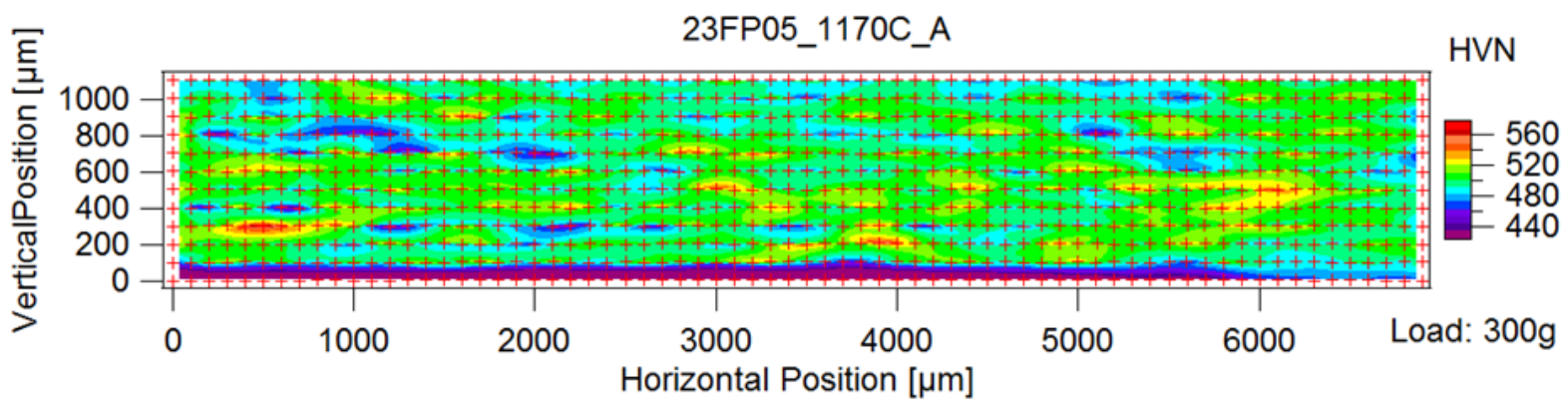

B.

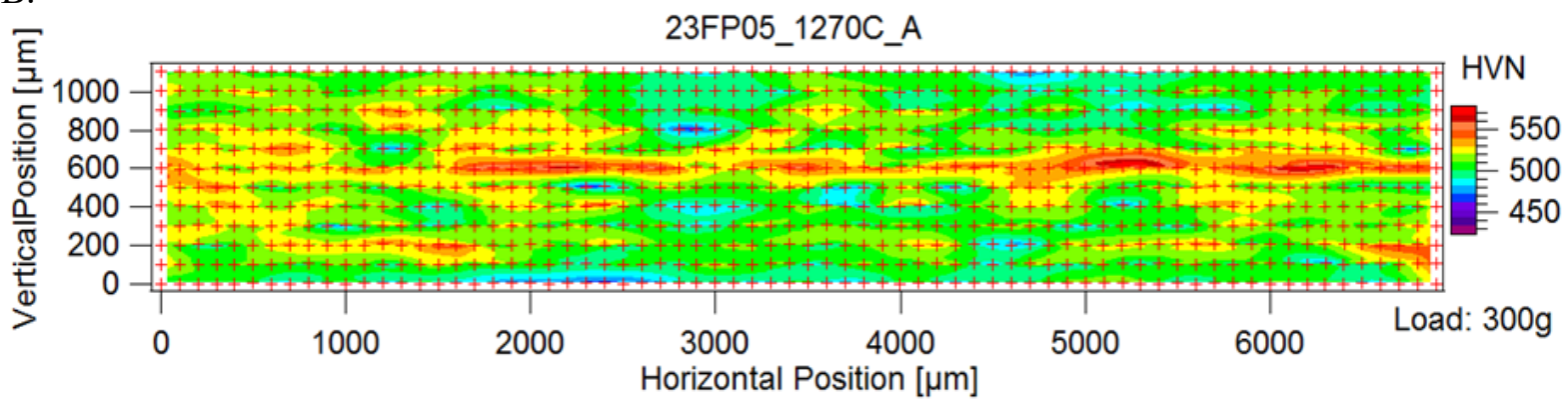

C.

Figure 20 - The hardness profiles for 1023 steel sheet flashed at A. $1070{ }^{\circ} \mathrm{C}, \mathrm{B} .1170{ }^{\circ} \mathrm{C}$, and C. $1270{ }^{\circ} \mathrm{C}$.
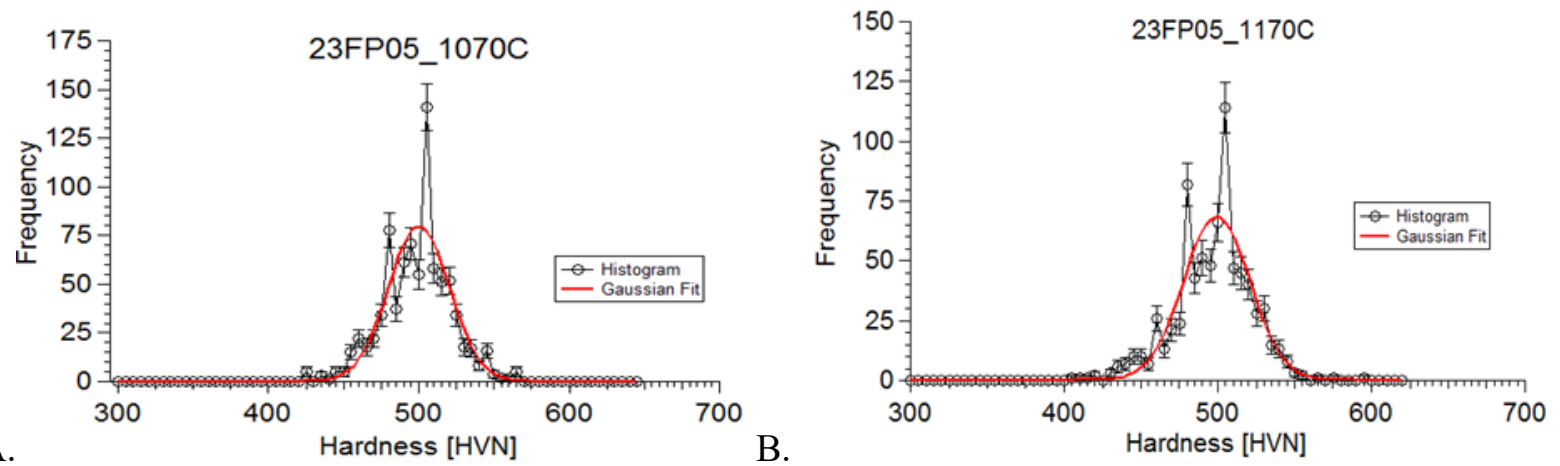


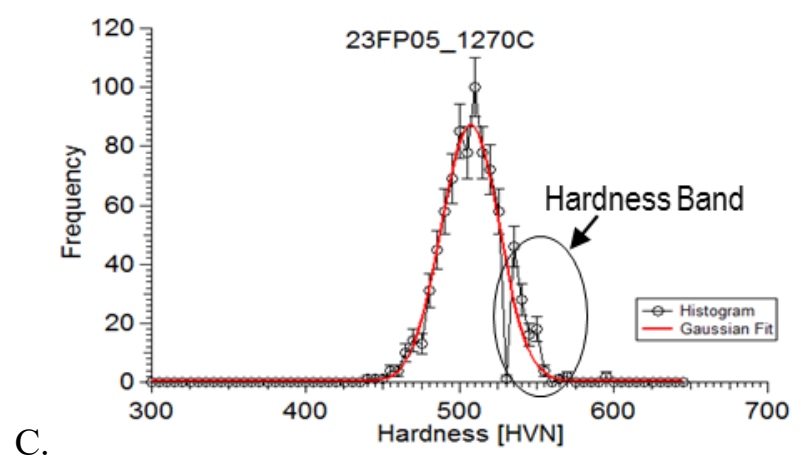

Figure 21 - The histograms of the hardness profiles from Figure 20 for A. $1070{ }^{\circ} \mathrm{C}, \mathrm{B} .1170{ }^{\circ} \mathrm{C}$, and C. $1270{ }^{\circ} \mathrm{C}$.

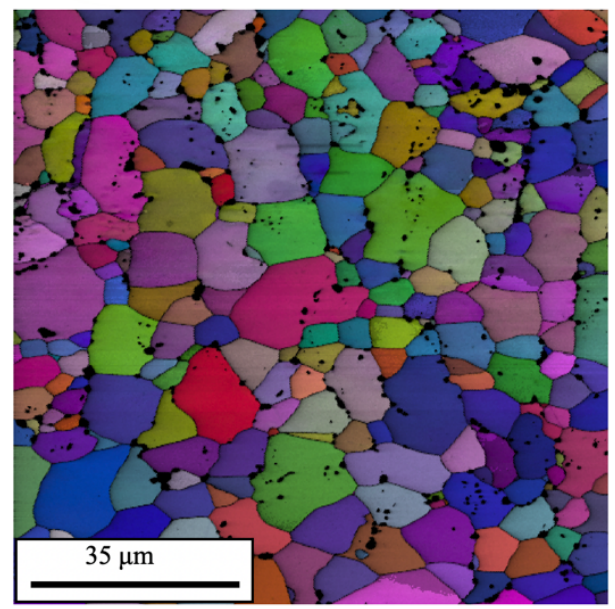

A. $1070^{\circ} \mathrm{C}$

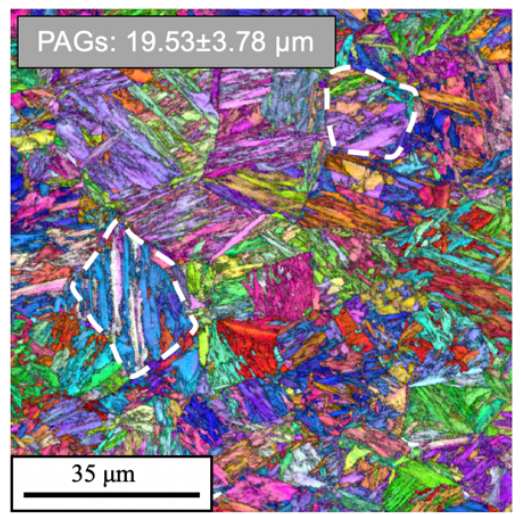

C.

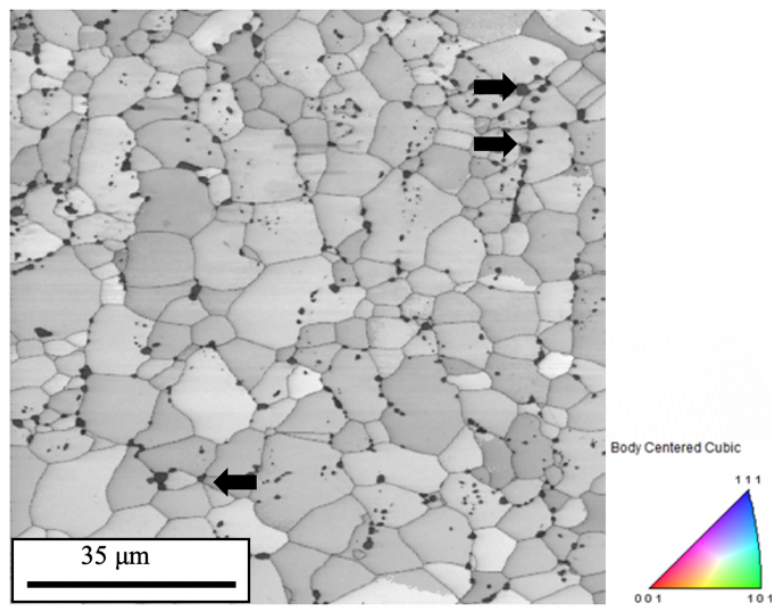

B. $1170^{\circ} \mathrm{C}$

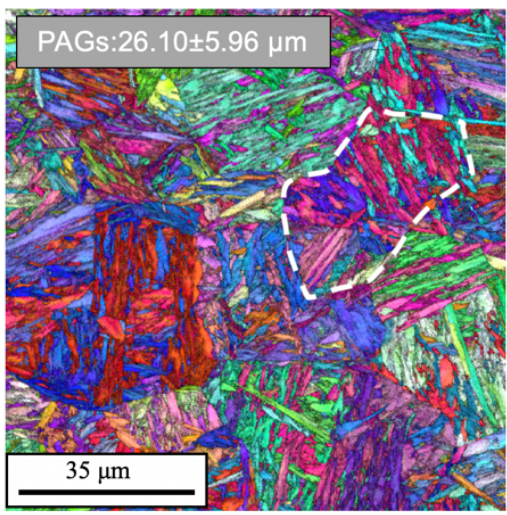

D. $1270^{\circ} \mathrm{C}$

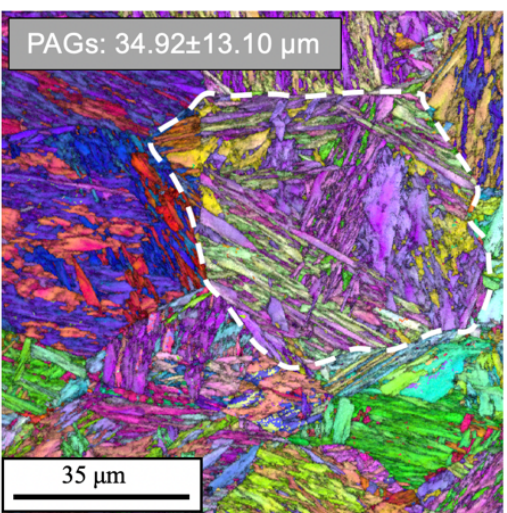

E.

Figure 22 - EBSD and SEM micrographs for 1023 steel sheet, as-received (A. \& B.) and EBSD micrographs for the as- flashed, C. $1070{ }^{\circ} \mathrm{C}$, D. $1170{ }^{\circ} \mathrm{C}$, and E. $1270{ }^{\circ} \mathrm{C}$. The colors in A., C., D., and E. indicate a particular crystallographic direction as given by the inverse pole figure ("triangular/pieshaped") legend to the right of B." The black arrows in B. indicate a few of the spheroidized carbide particles. The white dotted outlines in C., D., and E. highlight a prior austenite grain (PAG).

${ }^{*}$ Note that although the 111 reflection is extinct, EBSD is measuring orientation rather than reflections per se. Solving an EBSD pattern requires about a half-dozen distinct zones striking the camera to get a reliable solution. So, although (111) in BCC is an extinct direction, we can still measure the orientation of the [111] direction, and by geometry, the "virtual" (111) plane. 
backscattered diffraction (EBSD) micrographs of these samples taken on the top/external surface. In Figures 22A and B, the microstructure of as-received 1023 steel sheet appears to contain equiaxed ferrite $(\sim 20 \mu \mathrm{m}$ grain size $)$ and does not appear to be highly textured. Spheroidized carbides are also observed $(\sim 1-5 \mu \mathrm{m}$, see arrows in Figure 22B). The prior austenite grain (PAG) size increases with peak flash temperature from $19.5 \mu \mathrm{m}$ to $35 \mu \mathrm{m}$ (see Figures $22 \mathrm{C}$-E); the lathe size of martensite microstructure within the PAGs of samples is observed to be generally independent of peak flash temperature.

\section{A Third Set of Flash Processed Samples}

A 0.02 in $(0.5 \mathrm{~mm})$ thick sheet of 1010 steel was Flash processed at $1150^{\circ} \mathrm{C}$. A section of this sheet was then lightly stamped and "formed" at a stamping shop in Michigan. In addition, samples were cut from the same sheet and sent to a commercial testing lab for tensile testing. The remaining section of the flash processed sheet was shipped to ORNL for tensile testing and biaxial dome testing, providing a 1:1 correlation (previously not available) of stamping, tensile testing, and formability. In Figure 23, the residual section of 1010 sheet sent to ORNL is shown wherein tensile bars and dome testing disks were extracted. The tensile specimens shown have a noticeable curve/bow due to residual stresses from the Flash process. The curvature of these specimens is also exaggerated due to the small thickness of the sheet. The disks did not bow appreciably after extraction.

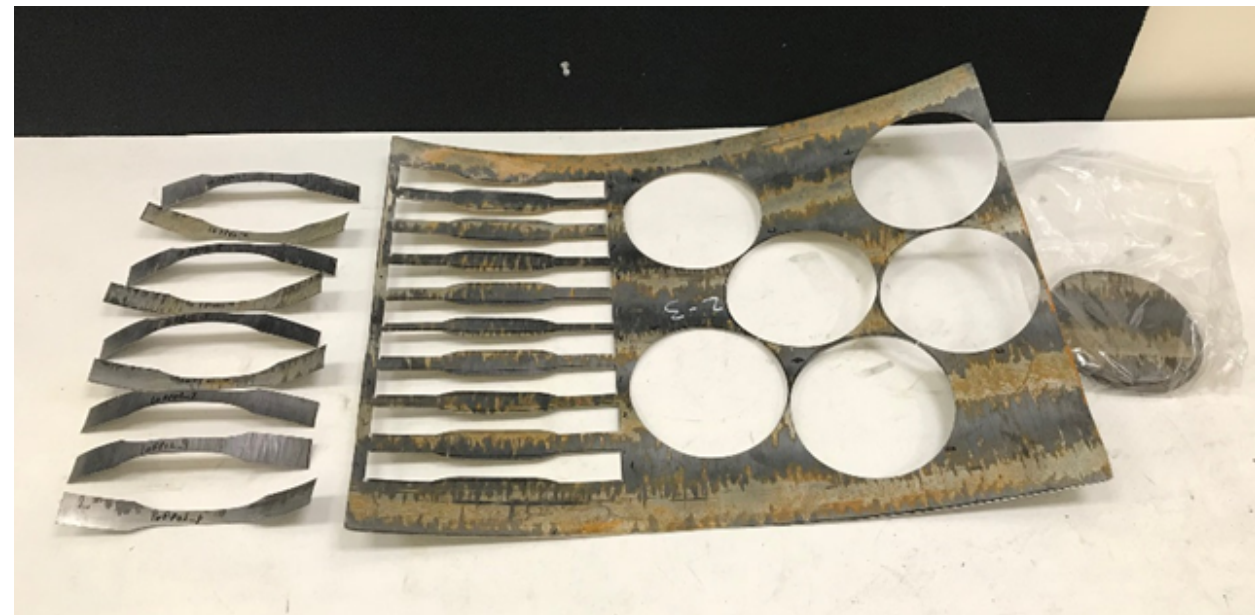

Figure 23 - 1010 sheet after Flash Processing and test specimens cut from the sheet.

Figure 24 shows the tensile stress versus strain curves for the 1010 sheet. The UTS (ultimate tensile strength) of the sheet ranged from 1100 to $1250 \mathrm{MPa}$. When comparing the data with the specimen tested at a commercial testing lab, all the specimens tested at ORNL had higher UTS's most likely due to loading rate differences between the two labs and/or location in the sheet from where the tensile sample was taken. While the elongation of the sheet ranged from $4 \%$ to $8 \%$, an interesting pattern emerged from the test. The two specimens nearest the edges of the sheet, one from each side, had close to $7 \%$ elongation (solid dark curves in Figure 24). Moving inward, the elongation of the adjacent samples dropped to 4\% (dark red curves) and was similar to the sample tested commercially. Closer to the center, the elongation increases to $8 \%$. It is unclear why the elongation drops and then increases at the center. 


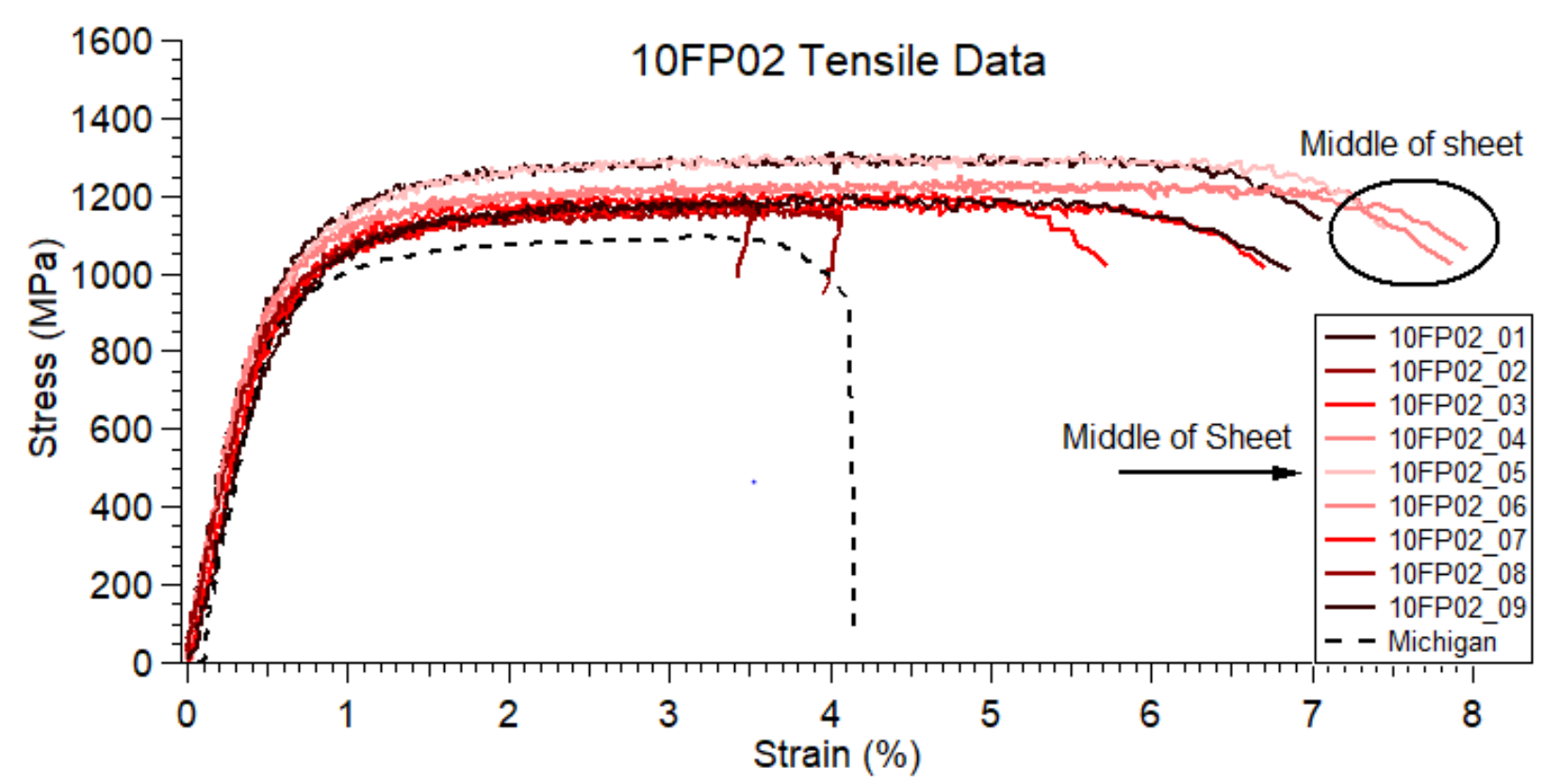

Figure 24 - Tensile data for the 1010 sheet. One curve from external testing is shown for comparison.

Figure 25 shows the load and normalized load versus dome displacement results for the corresponding biaxial tests. Unlike many of the other dome tests conducted at ORNL, all the samples were able to be clamped down prior to actual testing without cracking, which may be related to their relatively thin thickness. In Figure 25A, the biaxial load displacement curves for the flashed processed 1010 disks (see Figure 23) are shown (solid black lines) along with the results of the 1023 sheet with varied peak flash temperatures (solid yellow and orange curves) and the M1500 sheet (black dotted curves) for comparison. The maximum dome displacement for the 1010 flash processed sheet was $\sim 20 \mathrm{~mm}$. Figure 25B shows the thickness normalized results, wherein the 1010 curves are "in-line" with those of the 1023 and M1500 (declared standard). The reduced formability can be rationalized by the small thickness of the sheet. That is, the thinner the sheet, the less stretching or thinning the material can provide.
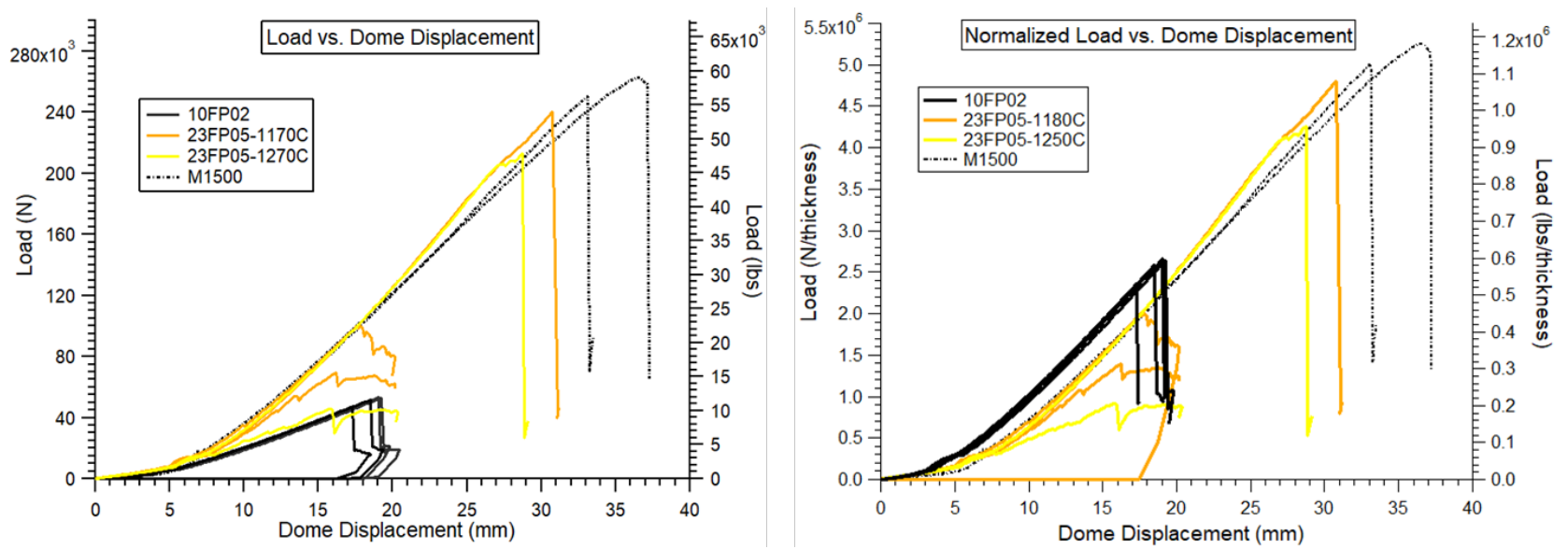

Figure 25 - A. Load as a function of dome displacement. B. thickness normalized load as a function of dome displacement. $\left(10 \mathrm{FP} 02=0.016 \mathrm{in}\right.$. thick 1010 steel flash processed at $1150^{\circ} \mathrm{C} ; 23 \mathrm{FP} 05-1170^{\circ} \mathrm{C}=$ $0.05 \mathrm{in}$. thick 1023 steel flash processed at $1170^{\circ} \mathrm{C} ; 23 \mathrm{FP} 05-1270^{\circ} \mathrm{C}=0.05 \mathrm{in}$. thick 1023 steel flash processed at $1270^{\circ} \mathrm{C}$; M1500 - unflashed commercially available martensitic steel). These last three curves are also found in Figure 19. 

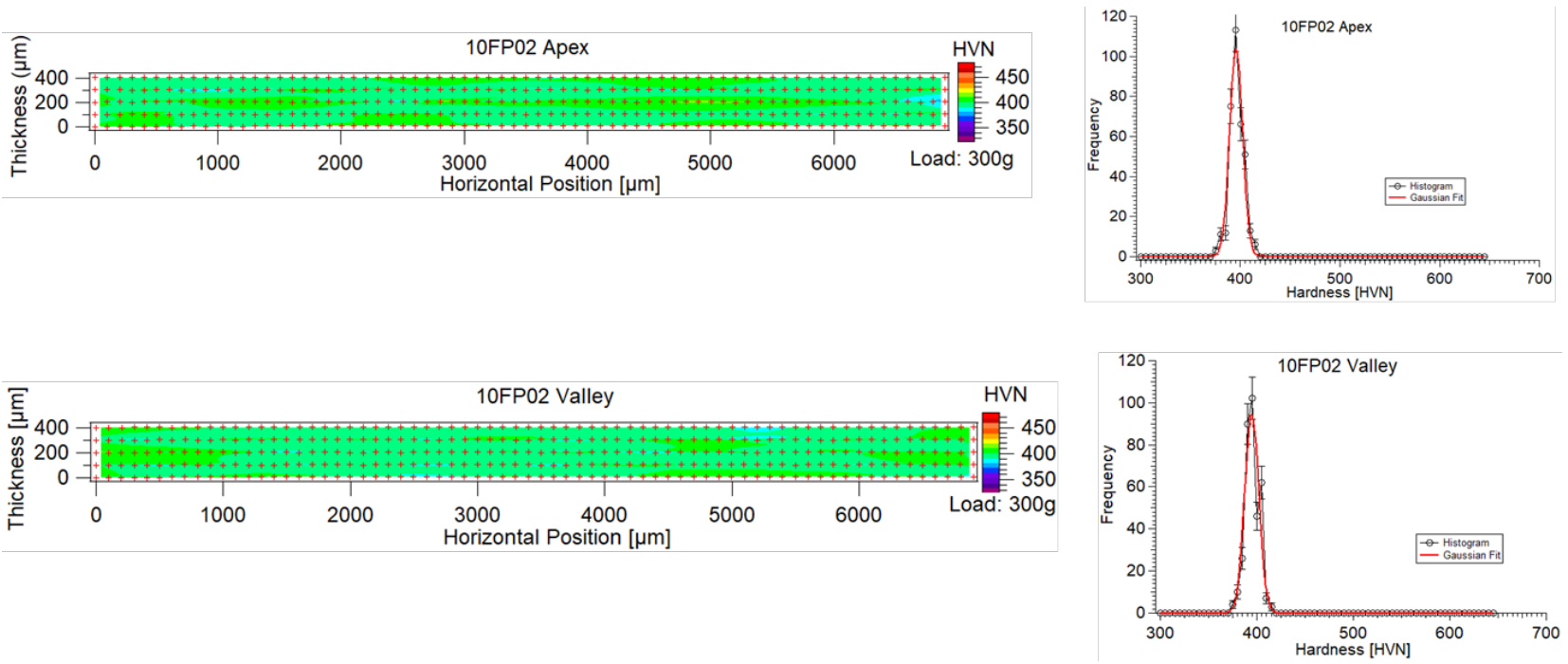

Figure 26 - Hardness maps and corresponding hardness histogram from flash processed 1010 steel at the apex/valley of the "wavy structure" of the flash processed sheet.

The tensile and formability testing for the $0.016 \mathrm{in} .(0.4 \mathrm{~mm})$ thick 1010 flash processed sheet (see Figures 24 and 25) are correlated with the corresponding hardness maps in Figure 26. The maps show the through thickness hardness at two of the "waves" or bends observed across the width of the flash processed sheet. Neither location showed any hardness heterogeneity. This is also shown in the histograms (left of the maps). In contrast, the range of hardness values in the $1.2 \mathrm{~mm}$ thick 1023 steel samples were roughly 100 HVN (see Figures 20 and 21), while the range was $<50 \mathrm{HVN}$ here. Also in contrast, there is an apparent lack of a hardness band in the center of the 1010 sheet. Both the reduced range of hardness values and lack of hardness band in the 1010 steel is most likely due to the reduced thickness of the sheet. The thermal gradients and resulting homogenization of alloying and interstitial elements within the $0.4 \mathrm{~mm}$ thick 1010 sheet will be different than those in the $1.3 \mathrm{~mm}$ thick 1023 sheet. In the 1023 sheets, the thickness of the hardness band is roughly 100-300 $\mu \mathrm{m}$. Whereas, the overall thickness of the 1010 sheet is $400 \mu \mathrm{m}$ and is apparently thin enough to have any inhomogeneities dissolved. Further investigation of the flash processed 1010 sheet was not pursued as the project was nearing its close.

\subsection{TASK 6: CORRELATION OF PROCESSING, STRUCTURE, AND PROPERTIES}

Transmission Electron Microscopy (TEM) was utilized to observed nano scale features of the microstructure and complement the hardness or SEM results. Figures 27A\&C and 27B\&D are from 1023 samples with peak flash temperatures of 1070 and $1270^{\circ} \mathrm{C}$, respectively. In Figures $27 \mathrm{~A}$ and $\mathrm{C}$, a few facetted aluminum nitride (AIN) particles are observed both near the surface as well as in the center of the sheet flash processed at $1070^{\circ} \mathrm{C}$. On the other hand, no AlN particles are found in the sample flash processed at $1270^{\circ} \mathrm{C}$. The presence and absence of AlN particles may have some bearing on the formability of flash processed material studied. The AlN particles could lead to "rock candy" [Flinn, 1963] fractures in the sheet which limits the ductility/formability of the sheet. The evolution of the AlN particles may be as follows. During continuous casting of the feedstock sheet, aluminum and nitrogen segregate mostly to the last remaining liquid (typically at the sample's center). Then during homogenization, spheroidization, or other heat treatment, AlN precipitates. When the sheet is flash processed at low temperature, these AlN precipitates do not dissolve. At higher flash processing 
temperatures, the AlN precipitates dissolve causing a local saturation of nitrogen. This saturation leads to nitrogen hardening, like the effect of carbon. The nitrogen hardening results in the hardness band at the center of the sheet (see Figure 20C). It is hypothesized that the presence or absence of the AlN particles have more impact on the formability than does the macro level microstructural features, such as the hardness band.

Figure 27 can be summarized as fine, nano-scale AlN (aluminum nitride) particles were observed at/near the center and edge, through thickness, of a sheet sample flash processed at a low peak temperature $\left(\sim 1070^{\circ} \mathrm{C}\right)$. In contrast, another sample of the same composition was flash processed at a higher peak temperature $\left(\sim 1270^{\circ} \mathrm{C}\right)$ and did not contain any AlN particles at/near the center or edge, through thickness, of a sheet. The absence of AlN particles in the high peak temperature sample indicated the possibility of AIN dissolution. As one TEM foil is small, the initial Transmission Electron Microscopy (TEM) work in Figure 27 could be construed as a sampling singularity/not representative.

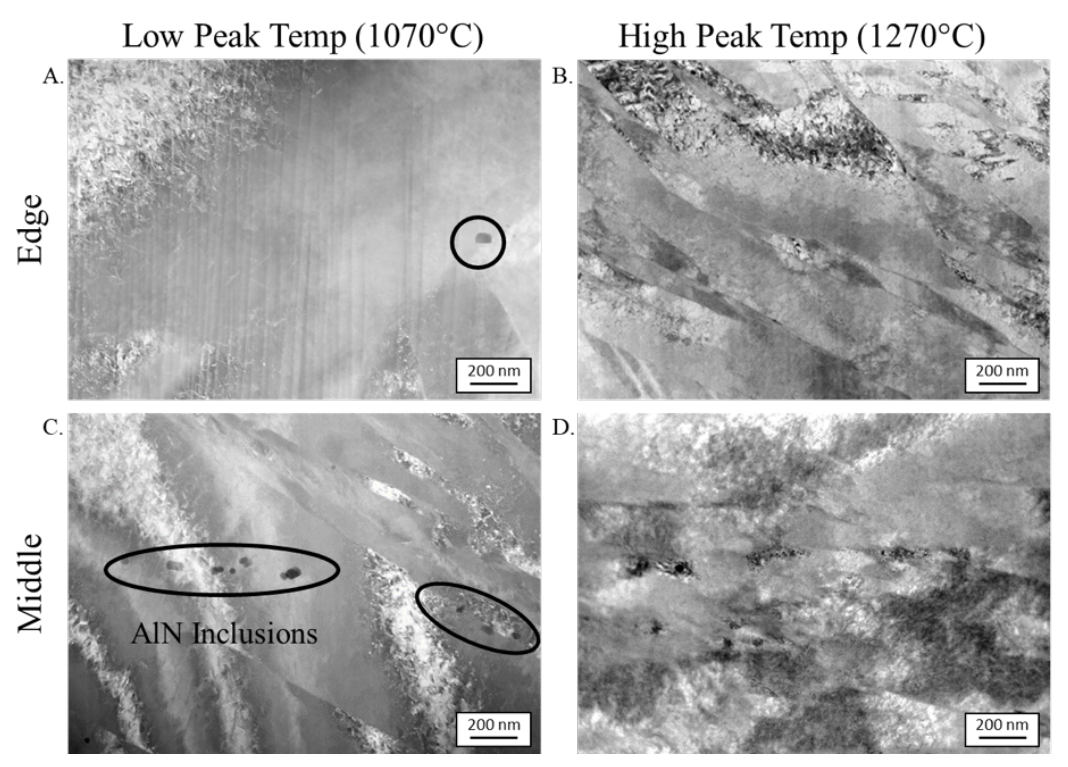

Figure 27 - A.\&B.) TEM bright field images from the edge $(250 \mathrm{~nm}$ from surface) and middle, through thickness, of the 1023 samples flash processed at 1070 and $1270^{\circ} \mathrm{C}$, respectively; C.\&D.) TEM images from the edge (as before) and middle of the sheet from the 1023 samples flash processed at 1070 and $1270^{\circ} \mathrm{C}$, respectively. 
In response, two more samples were taken from these same Flashed sheets to reproduce/confirm the presence of AlN at the lower flash processing temperatures and dissolution at the higher. In this second round of TEM work, similar results were found to the first. In the lower flash temperature sample $\left(\sim 1070^{\circ} \mathrm{C}\right)$, approximately 16 and 20 AlN particles can be observed near the edge and in the middle of the sample (see Figure 28A and C), respectively. In contrast, only $2 \mathrm{AlN}$ particles were observed in the middle of the high peak temperature sample (see Figure 28D), and none were observed in the edge of the sample (see Figure 28B). This result was attributed to the higher flash processing temperature $\left(\sim 1270^{\circ} \mathrm{C}\right)$ dissolving these particles. Thermodynamic calculations using ThermoCalc software predicted AlN should be dissolved at $1270^{\circ} \mathrm{C}$ (see below).

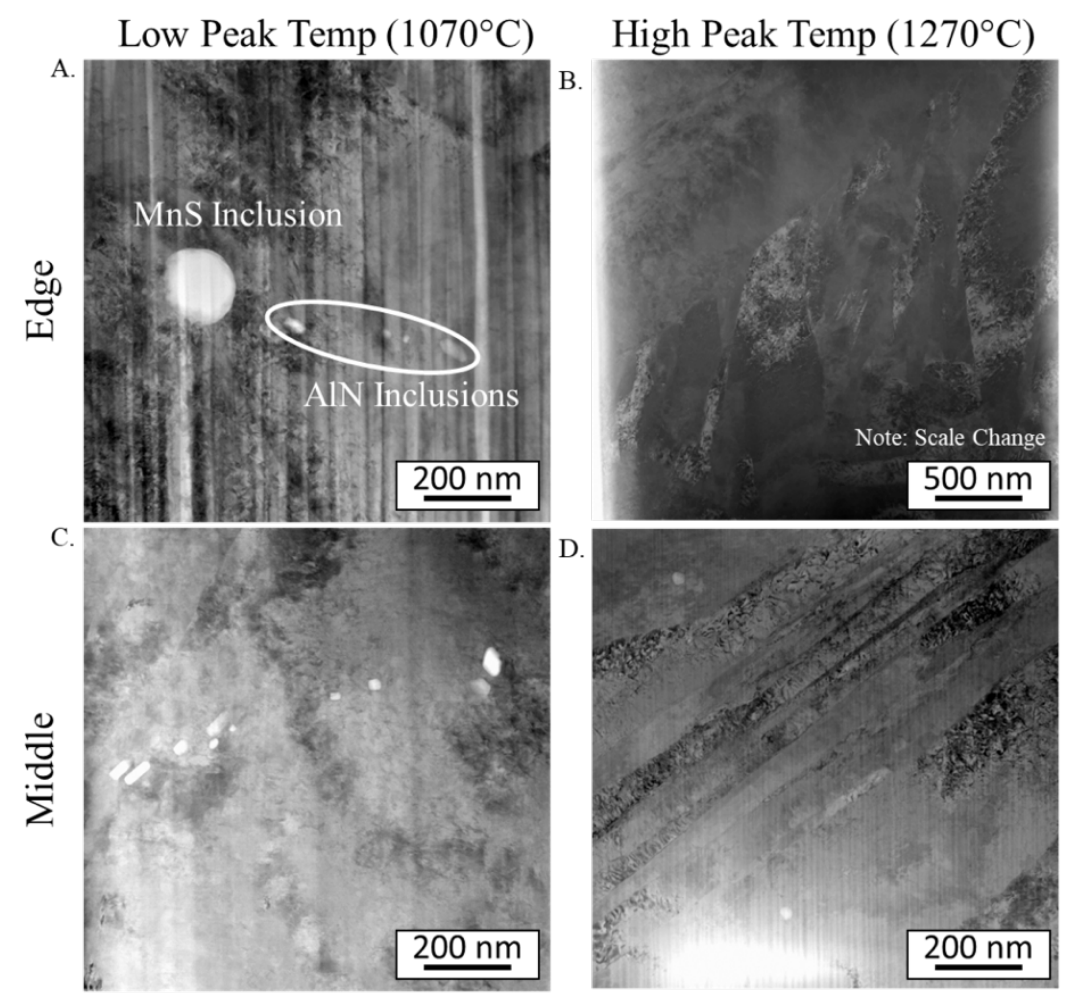

Figure 28 - A.\&B.) A second set of TEM dark field images from a second set of 1023 samples flash processed at 1070 and $1270^{\circ} \mathrm{C}$ taken at the edge $(250 \mathrm{~nm}$ from surface) and middle, through thickness, respectively; C.\&D.) TEM images from the edge (as before) and middle of the sheet from the 1023 samples flash processed at 1070 and $1270^{\circ} \mathrm{C}$, respectively. 
Thermodynamic calculations support the presence of AlN at temperatures less than $1100^{\circ} \mathrm{C}$. Figure $29 \mathrm{~A}$ shows the solubility curves of AlN at various temperatures with the $\mathrm{Al}$ and $\mathrm{N}$ content in the steel. Therein, the blue dot locates the $\mathrm{Al}$ and $\mathrm{N}$ content, as provided by vendor, of the bulk 1023 sheet. Its location indicates, assuming equilibrium conditions, that AlN should not dissolve (insoluble) until a peak temperature of $\sim 1150^{\circ} \mathrm{C}$ is reached. Figure 29B shows the equilibrium curves for this alloy composition and has been scaled to highlight the inclusions in the steel. Starting at $500^{\circ} \mathrm{C}$ and increasing temperature, the red vertical line at $727^{\circ} \mathrm{C}$ defines where BCC iron starts to form FCC. Next is the blue/aqua vertical line defines where carbides (labelled graphite, $\sim 730^{\circ} \mathrm{C}$ ) start to dissolve. Continuing to higher temperatures the olive vertical line defines where the iron is now $100 \% \mathrm{FCC}\left(\sim 800^{\circ} \mathrm{C}\right)$. The light purple, red (again) and olive (again) vertical lines, near nominally $1500^{\circ} \mathrm{C}$, define where the liquid starts to form, delta ferrite starts to form and where the iron is now $100 \%$ delta, respectively. The yellow equilibrium curve shows that the AlN should all dissolve at $\sim 1125^{\circ} \mathrm{C}$. Figure $29 \mathrm{~B}$ also shows AlN having a greater volume fraction than the $\mathrm{MnS}$ and $\mathrm{Al}_{2} \mathrm{O}_{3}$ inclusions (green and dark purple curves, respectively). Thus, it can be expected that AlN inclusions could impact the forming of the sheet, causing fracture origins, more than the other inclusions. As a check, additional 1023 alloy samples have been submitted to a testing lab for chemistry determinations (see Appendix A), which shows there is sufficient amount of aluminum (16 ppm moles) to tie up both nitrogen (4 ppm moles) and oxygen (9 ppm moles). Aluminum levels could vary significantly with various grades of sheet steel depending on steelmaking practice, which could lead to a lot of variability in properties of improperly flashed sheet.

a

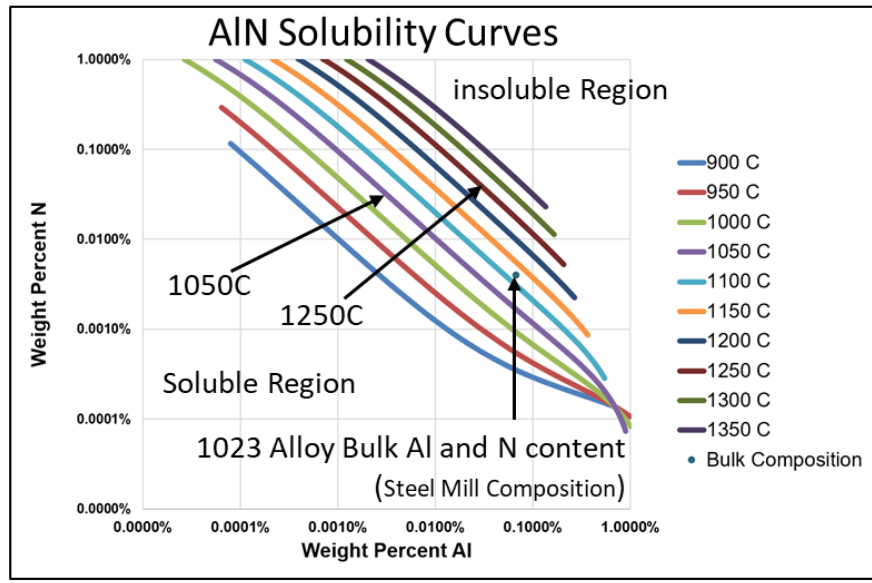

Equilibrium Curves

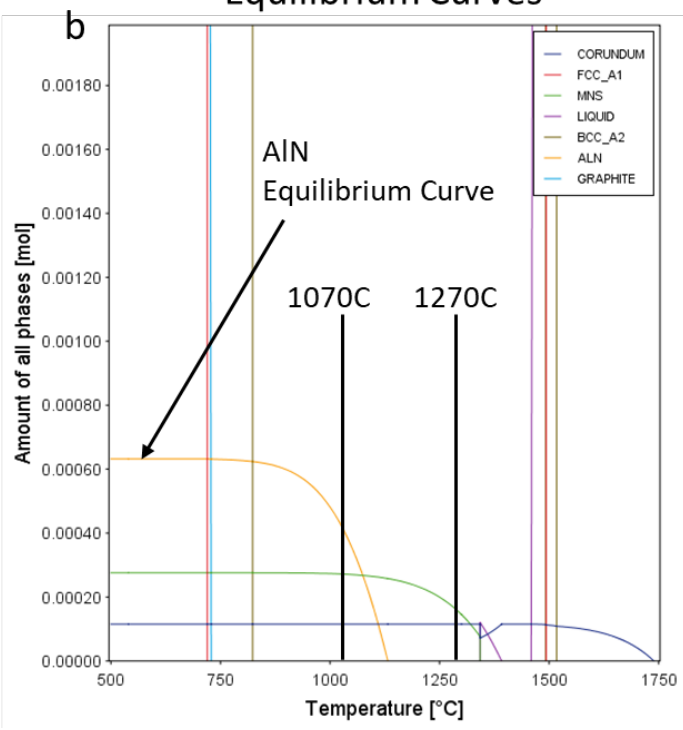

Figure 29 - A. Aluminum Nitride solubility diagram. B. Equilibrium curves for the composition of the 1023 sheet (note: the curve deviations at $\sim 1300^{\circ} \mathrm{C}$ are not real and originate from the thermodynamic software's inability to handle the junction at very low fractions).

\subsection{TASK 7: MODELING OF THERMAL TRANSHENTS AND FORMABHLITY}

Given the difficulties with forming based on the initial flash processing, this task simply became out of scope given the difficulties in temperature measurement. 


\subsection{TASK 8: PRODUCE GUIDELINES FOR SCALING UP FLASH PROCESSING}

As water and/or steam absorb the Infra-Red (IR) signal almost completely, IR pyrometry will not work unless a direct line of sight is maintained between the pyrometer and the hot work piece. Although this direct line of sight may be possible with the new Flash Coil Line, optical pyrometric measurements will be the main temperature measurement technique going forward. Based SFP Works single color pyrometer temperature measurements, the peak heating or Flash temperature must increase above the standard flash temperature SFP employs (from $1000-1100^{\circ} \mathrm{C}$ to $>1170-1270^{\circ} \mathrm{C}$ ), which provides slightly less elongation ( 8 vs. $9 \%$ ), but unexpectedly improves "formability" as observed in the dome testing. This guidance will be employed in the operation of the Flash Coil line in FY2020.

\subsection{PUBLICATION AND PRESENTATION}

Benjamin Shassere, Sudarsanam Suresh Babu, Gary Cola, Thomas Muth, Thomas R. Watkins, "Microstructure Control and Correlation to Formability of Low Alloy Steel Via Flash Processing," presented by Benjamin Shassere at MS\&T18 (Material Science \& Technology Technical Meeting and Exhibition), Columbus, OH, October 15, 2018.

B. Shassere, S. S. Babu, G. Cola, T. Muth, T. R. Watkins, "Microstructure Control and Correlation to Formability of Low Alloy Steel Via Flash Processing," submitted to the Proceedings of MS\&T18, October 15, 2018.

\subsection{REFERENCES}

W. Gan, S.S. Babu, N. Kapustka, R. H. Wagoner, "Microstructural Effects on the Springback of Advanced High-Strength Steel” Met. \& Mater. Trans. 37A (11) (2006) 3221.

R. A. Flinn, Fundamentals of Metal Casting. 1963, Reading, MA: Addison-Wesley, p. 215.

David R. Forrest, Theresa Miller, S.S. Babu, Benjamin Shassere, and G.M. Cola Jr., "Flash ${ }^{\circledR}$ Processing for High-Strength, Cold-Stampable Automotive Steel," Industrial Heating, May 2017, https://www.industrialheating.com/articles/93495-flash-processing-for-high-strength-cold-stampableautomotive-steel.

T. Lolla, G. Cola, B. Narayanan, B. Alexandrov, S.S. Babu, "Development of rapid heating and cooling (flash processing) process to produce advanced high strength steel microstructures," Materials Science and Technology 27(5) (2013) 863-875.

T. R. Watkins et al., DOE Quarterly Progress Reports, Fundamental Science and Technology of Flash Processing Robustness for Advanced High Strength Steels (AHSS), Quarter 2, FY2016 to Quarter 3, FY2019. 


\title{
APPENDIX A. Chemical Analyses of 1023 Steel Samples
}

\author{
Lexicon \\ $\mathrm{AR}=$ as-received \\ Ben $1960=$ Flashed at $1960^{\circ} \mathrm{F} / 1070^{\circ} \mathrm{C}$ \\ Ben $2270=$ Flashed at $2270^{\circ} \mathrm{F} / 1243=1250^{\circ} \mathrm{C}$
}


Luvak Inc.

722 Main Street

P.O. Box 597

Boylston, MA 01505

Phone 508-869-6401

Requested by:

Oak Ridge National Laboratories

1 Bethel Valley Road

P.O. Box 2008

Oak Ridge, TN 37831-6083

Invoice number: 91503

Customer Purchase Order no.: 20AMSL6250
Analytical report no. 0-86308

Page 1 of 2

Attention: Benjamin Shassere shassereba@ornl.gov

Date received: $11 / 12 / 18$ Report date: $11 / 29 / 18$ Invoice date: 11/29/18

Description: Four Steel based samples were analyzed as listed below.

Results:

\begin{tabular}{|c|c|c|c|c|}
\hline Sample Identification: & Ben AR & Ben AR & $\underline{\text { Ben 1960 }}$ & Ben 1960 \\
\hline & $\underline{\%}$ & $\underline{\%}$ & $\underline{\%}$ & $\underline{\%}$ \\
\hline Oxygen & .014 & .014 & .008 & .008 \\
\hline Nitrogen & .006 & .006 & .006 & .005 \\
\hline Carbon & .234 & .226 & .236 & .229 \\
\hline Sulfur & .006 & .006 & .007 & .007 \\
\hline Manganese & .43 & .43 & .41 & .45 \\
\hline Chromium & .033 & .031 & .032 & .033 \\
\hline Silicon & .030 & .027 & .032 & .033 \\
\hline Nickel & .023 & .019 & .018 & .018 \\
\hline Aluminum & .046 & .048 & .047 & .043 \\
\hline Phosphorus & .009 & .004 & .006 & .007 \\
\hline
\end{tabular}

Methods: Oxygen \& Nitrogen - Inert gas fusion - ASTM E 1019-18

Carbon \& Sulfur - Combustion infrared detection - ASTM E 1019-18

All Others - Direct current plasma emission spectroscopy - ASTM E 1097-12

Luvak Inc. utilizes the ASTM E29 rounding method unless specification or customer designates otherwise.

The analytical report shall not be reproduced, except in full, without the written approval of the laboratory. The recording of false, fictitious or fraudulent statements or entries on the analytical report may be punished as a felony under federal law.

Luvak Inc.

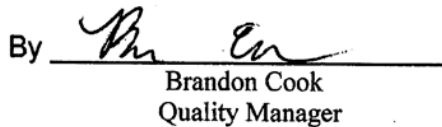


Luvak Inc.

722 Main Street

P.O. Box 597

Boylston, MA 01505

Phone 508-869-6401

Requested by:

Oak Ridge National Laboratories

1 Bethel Valley Road

P.O. Box 2008

Oak Ridge, TN 37831-6083

Invoice number: 91503

Customer Purchase Order no.: 20AMSL6250
Analytical report no.

$0-86308$

Page 2 of 2

Attention:

Benjamin Shassere shassereba@ornl.gov

Date received: $11 / 12 / 18$

Report date: $11 / 29 / 18$

Invoice date: $11 / 29 / 18$

Description: Two Steel based samples were analyzed as listed below. Results:

\begin{tabular}{|c|c|c|}
\hline Sample Identification: & Ben 2270 & $\underline{\text { Ben 2270 }}$ \\
\hline & $\underline{\%}$ & $\underline{\%}$ \\
\hline Oxygen & .009 & .009 \\
\hline Nitrogen & .006 & .006 \\
\hline Carbon & .232 & .229 \\
\hline Sulfur & .007 & .007 \\
\hline Manganese & .42 & .38 \\
\hline Chromium & .032 & .031 \\
\hline Silicon & .029 & .030 \\
\hline Nickel & .018 & .017 \\
\hline Aluminum & .046 & .046 \\
\hline Phosphorus & .006 & .006 \\
\hline
\end{tabular}

Methods: Oxygen \& Nitrogen - Inert gas fusion - ASTM E 1019-18

Carbon \& Sulfur - Combustion infrared detection - ASTM E 1019-18

All Others - Direct current plasma emission spectroscopy - ASTM E 1097-12

Luvak Inc. utilizes the ASTM E29 rounding method unless specification or customer designates otherwise.

The analytical report shall not be reproduced, except in full, without the written approval of the laboratory. The recording of false, fictitious or fraudulent statements or entries on the analytical report may be punished as a felony under federal law.

Luvak Inc.

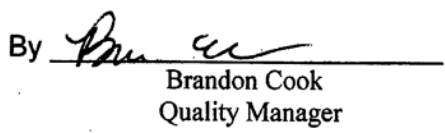

